\title{
Identification of QTLs for yield and agronomic traits in rice under stagnant flooding conditions
}

\author{
Anshuman Singh ${ }^{1,4}$, Jerome Carandang ${ }^{4}$, Zennia Jean C. Gonzaga ${ }^{4}$, Bertrand C. Y. Collard ${ }^{2,4}$, Abdelbagi M. Ismail ${ }^{4}$ \\ and Endang M. Septiningsih ${ }^{3,4^{*}}$
}

\begin{abstract}
Background: Stagnant flooding, where water of $25-50 \mathrm{~cm}$ remains until harvest time, is a major problem in rainfed lowland areas. Most of the Sub1 varieties, which can withstand around 2 weeks of complete submergence, perform poorly in these conditions. Hence, varieties tolerant of stagnant flooding are essential.

Results: This paper presents the first study to map QTLS associated with tolerance to stagnant flooding, along with a parallel study under normal irrigation, using an $\mathrm{F}_{7}$ mapping population consisting of 148 RILs derived from a cross of Ciherang-Sub1 and the stagnant-flooding tolerant line IR10F365. Phenotypic data was collected for 15 key traits under both environments. Additionally, survival rate was measured under stress conditions. Genotyping was performed using the Illumina Infinium genotyping platform with a $6 \mathrm{~K}$ SNP chip, resulting in 469 polymorphic SNPs. Under stress and irrigated conditions, 38 and 46 QTLs were identified, respectively. Clusters of QTLs were detected in both stress and normal conditions, especially on chromosomes 3 and 5.

Conclusions: Unique and common QTLs were identified and their physiological consequences are discussed. These beneficial QTLs can be used as targets for molecular breeding and can be further investigated to understand the underlying molecular mechanisms involved in stagnant flooding tolerance in rice.
\end{abstract}

Keywords: Irrigated rice, Oryza sativa, QTL, Rainfed rice, Stagnant flooding, Sub1 varieties

\section{Background}

Most of rainfed lowlands and some irrigated areas in South and Southeast Asia are prone to flooding which causes huge crop losses worldwide. This situation may worsen under future climate change scenarios (Redfern et al. 2012). Floods are largely caused by incessant rainfall during the monsoon season from mid-June to early October, often causing complete submergence followed by stagnant flooding in areas with poor drainage, resulting in huge financial losses (Singh et al. 2011). Rice has developed adaptive mechanisms to survive under a wide range of water regimes; however, extreme weather leading to too much or too little water may cause serious yield reductions or total crop loss.

\footnotetext{
* Correspondence: eseptiningsih@tamu.edu

${ }^{3}$ Present address: Department of Soil and Crop Sciences, Texas A\&M University, College Station, TX 77843, USA

${ }^{4}$ International Rice Research Institute, DAPO 7777, Metro Manila, Philippines Full list of author information is available at the end of the article
}

Different types of flooding can reduce rice production. Flash flooding is the most common, which occurs when rice plants are completely submerged for up to 2 weeks during the vegetative stage. If submergence prevails for more than 5 days, susceptible rice plants start to die and recovery is hampered (Mackill et al. 2010). Fortunately, a number of Sub1 varieties have been developed and released as remedies for this type of flooding, as the Sub1 gene enables the submerged plants to become dormant and conserve resources for a rapid recovery after the floods recede. The first generation of Sub1 lines were the first six varieties developed by the International Rice Research Institute (IRRI), including Swarna-Sub1, IR64-Sub1, Samba Mahsuri-Sub1, BR11-Sub1, TDK1Sub1, and CR1009-Sub1. While the second generation of Sub1 lines developed by IRRI were Ciherang-Sub1 and PSB Rc18-Sub1 in which IR64-Sub1 was used as the donor for the SUB1 gene (Iftekharuddaula et al. 2011; 
2016; Ismail et al. 2013; Neeraja et al. 2007; Septiningsih et al. 2009, 2015). Another type of flooding stress is flooding during germination, also known as anaerobic germination (AG). This can be due to unlevelled fields in direct-seeded rainfed or irrigated environments, especially in flood affected areas, when rain falls just after seeding causing poor seedling establishment (Ismail et al. 2009). Several major QTLs for tolerance to AG have been identified (Angaji et al. 2010; Baltazar et al. 2014; Septiningsih et al. 2013b) and a few lines with tolerance to AG alone or combined with SUB1 have been developed through molecular and conventional breeding (Kretzschmar et al. 2015; Septiningsih et al. 2013a; Toledo et al. 2015). Some rainfed areas are also affected by deep water flooding where water stagnation is more than $1 \mathrm{~m}$. In this situation, deepwater adapted varieties with fast internode elongation are required to escape from water while their shoot tips and tillers remain above the water (Catling 1992; Hattori et al. 2009). QTLs and genes have been identified and some tolerant lines have been developed for this type of flooding (Hattori et al. 2008, 2009).

The last type of flooding stress, which is the focus of this study, is stagnant flooding (SF), where water of 25 to $50 \mathrm{~cm}$ depth stagnates in the field for several weeks to few months (Mackill et al. 2010; Singh et al. 2011). In this stress environment, varieties with facultative elongation are needed; however, deepwater rice performs poorly under stagnant flooding conditions mainly due to lodging and the consequent reductions in yield and grain quality (Kato et al. 2014; Vergara et al. 2014). At the same time, most irrigated rice varieties also perform poorly under these conditions, as water depth greater than $25 \mathrm{~cm}$ greatly inhibits the growth of rice. The detrimental effect of SF can be seen as reduced number of tillers, poor fertility, smaller panicles and excessive lodging; together leading to poor grain yield and quality (Kato et al. 2014; Singh et al. 2014). The situation worsens when floods result in complete submergence followed by stagnant flooding until harvest time (Singh et al. 2011). Therefore, it is essential to develop varieties having tolerance of complete submergence during vegetative stage and stagnant flooding in the same genetic background. Farmers mostly use traditional low-yielding landraces in areas that are prone to both stresses within the same season. These landraces have partial tolerance of complete submergence and can resist stagnant flooding stress by stem and leaf elongation, but they have low yield of around $0.5-1.5 \mathrm{t} \mathrm{ha}^{-1}$ and low quality (Singh et al. 2011). The introgression of SUB1 QTL in several mega varieties successfully improved submergence tolerance with a yield advantage of $2-3.5 \mathrm{t} \mathrm{ha}^{-1}$ in farmers' fields (Singh et al. 2009). However, these varieties perform poorly under stagnant flooding conditions, especially since most of the Sub1 varieties are relatively short, making the plants more prone to damage if water depth stays up to canopy level for longer than 2 weeks (Singh et al. 2011).

Conventional breeding to develop improved varieties with stagnant flooding has long been conducted at IRRI, and some tolerant lines have been developed (Collard et al. 2013; Mackill et al. 2010). Thus far, however, studies on genetic and molecular basis of stagnant flooding had not been initiated. In this study we report for the first time, the identification of QTLs under stagnant flooding conditions from an $\mathrm{F}_{7}$ RIL population derived from a cross of the improved version of the popular highyielding Indonesian variety, Ciherang-Sub1 (IR09F436) (Septiningsih et al. 2015) and an IRRI submergence and stagnant flooding tolerant breeding line, IR10F365 (Collard et al. 2013) using an Illumina 6 K SNP chip platform (Thomson 2014). A subset of this RIL population was recently used in our study to identify non-Sub1 QTLs for tolerance to submergence during vegetative stage (Gonzaga et al. 2017). In the current study, 15 traits related to yield and important agronomic traits were investigated in both stagnant flooding and normal irrigated field conditions. The parallel study under control irrigated conditions is also valuable since the RIL population was developed using a popular cultivar (Ciherang-Sub1) and an elite line (IR10F365) which are both high yielding lines. Additionally, it allows detecting QTLs associated with responses induced by stagnant flooding versus inherent responses, with the former being most important for breeding varieties adapted to stagnant flooding conditions.

\section{Methods}

\section{Plant material and development of the mapping population}

A RIL mapping population was developed comprising of $156 \mathrm{~F}_{7}$ lines derived from a cross of Ciherang-Sub1 with IR10F365. Both parents carry the tolerant allele of the SUB1 gene (i.e. Sub1 gene was fixed in this population), which contributes to tolerance to submergence during vegetative stage. A subset of 115 RILs from this population was used to map non-Sub1 QTLs for submergence tolerance during vegetative stage (Gonzaga et al. 2017); however, in this current study the entire population of 156 RILs was used. During the final analysis, however, 8 lines were removed due to high levels of missing genotype or phenotype data, resulting in a final set of 148 RILs. Other than the two parents, Swarna-Sub1 and IRRI154 were also included as susceptible and tolerant checks, respectively. IRRI154 (also known as NSIC Rc222) is a popular high-yielding irrigated rice variety released in the Philippines. This variety is highly tolerant to stagnant flooding but susceptible to complete submergence during vegetative stage. Swarna-Sub1 is the first submergence tolerant variety released in South Asia (Neeraja et al. 2007). 


\section{Experimental field conditions}

The mapping population was evaluated in 2014 wet season (WS) in the field plots at the International Rice Research Institute (IRRI), Los Baños, Laguna, Philippines $\left(14^{\circ} 10^{\prime} 11.81^{\prime \prime} \mathrm{N}, 121^{\circ} 15^{\prime} 39.22^{\prime \prime} \mathrm{E}\right)$ under stagnant flooding stress and normal irrigated conditions. A row-column design was used with two replications, with planting distance of $20 \times 20 \mathrm{~cm}$ in individual plots of $5 \times 0.8 \mathrm{~m}$ under stress condition. The same population was planted under controlled irrigation using the same experimental design and planting conditions following standard agronomic practices. Besides the two parents, IRRI154 and Swarna-Sub1 were also included as checks. Fertilizer was applied at three stages as recommended at basal, maximum tillering and panicle initiation. Seeds were sown in raised seed bed nursery and $16 \mathrm{~d}$-old seedlings were transplanted in the submergence plot with one seedling per hill. The water in the SF plot was raised to $10 \mathrm{~cm}$ at 2 weeks after transplanting (WAT) and was gradually increased by $5 \mathrm{~cm}$ each week until the $6^{\text {th }}$ WAT. Thereafter, water was raised gradually by $10 \mathrm{~cm}$ until the $8^{\text {th }}$ WAT, for a final depth of $50 \mathrm{~cm}$. During this period plants were at maximum tillering stage, and this condition was maintained up to harvesting time. Water depth in the control field was kept at about $5 \mathrm{~cm}$ through maturity.

\section{Phenotyping and data analysis}

Sixteen traits selected based on previous physiological studies of stagnant flooding tolerance or related studies were investigated (Hattori et al. 2007; Hattori et al. 2008; Kato et al. 2014; Nagai et al. 2014; Singh et al. 2011; Vergara et al. 2014). Those traits were: days to flowering (DTF), plant height $(\mathrm{PH})$, shoot elongation rate (SER), number of tillers (TN), number of panicles (PN), 100 grain weight $(\mathrm{GW})$, shoot biomass $(\mathrm{BM})$, flag leaf length (FLL), flag leaf width (FLW), panicle length (PL), harvest index (HI), leaf sheath length for the first, second and third internodes $\left(\mathrm{LSL}_{1}, \mathrm{LSL}_{2}\right.$, and $\mathrm{LSL}_{3}$, respectively), grain yield per plot (GY), and survival rate (SR). The same traits were measured under irrigated condition for direct comparisons, except SR. Details of phenotyping are provided in Additional file 1: Table S1. Data were analyzed using PB Tools 1.4 and STAR (http://bbi.irri.org/ products). Analysis of variance (ANOVA) and correlation analysis were performed. Means were estimated using linear mixed models and broad-sense heritability $\left(\mathrm{H}^{2}\right)$ was calculated using PBTools.

\section{Genotyping}

Total genomic DNA was extracted using a modified CTAB technique (Murray and Thompson 1980), and the final concentration was normalized to $50 \mathrm{ng} / \mu \mathrm{L}$. Genotyping was performed using the Illumina Infinium genotyping platform with a $6 \mathrm{~K}$ SNP chip designed by Susan McCouch at Cornell University and run at the Genotyping Services Laboratory, IRRI (Thomson 2014), as described previously (Gonzaga et al. 2017).

\section{QTL analysis and linkage map construction}

Map Manager QTX, vQTXb20 (Manly et al. 2001) was used for linkage map construction with Kosambi map function. Due to high rates of missing data in 8 lines, only 148 RILs were used in the final analysis. QTL analysis was performed using QTL Cartographer v2.5 (Wang et al. 2010) with 1,000 permutations in both interval mapping (IM) and composite interval mapping (CIM) methods to determine the threshold at $P \leq 0.05$ and $P \leq 0.01$ to declare the significance of QTLs. Forward-backward stepwise regression of F-in $=0.01$ and F-out $=0.01$ was used in CIM. For comparison, QGene (Nelson 1997) was also used based on IM and CIM with permutation of 10,000 iterations. Standard rice QTL nomenclature was used (McCouch 2008).

\section{QTL comparison}

QTLs identified in this study were compared with similar QTLs identified in previous studies using the Gramene QTL database (http://archive.gramene.org/qtl/) and QTL Annotation Rice Online (Q-TARO) database (http://qtaro.abr.affrc.go.jp/) (Yonemaru et al. 2010). QTLs for the same traits sharing similar regions between the irrigated and stagnant flooding environments and clusters of QTLs governing various traits located in similar regions are also reported.

\section{Results and Discussion}

\section{Performance of parents and checks}

SUB1A suppresses shoot elongation during complete submergence to limit carbohydrate consumption and increase chances of survival after water recedes; but this can lead to a disadvantage if submergence is followed by a longer duration of stagnant flooding (Sarkar et al. 2009; Singh et al. 2009). It was also reported that the first six Sub1 lines developed by IRRI (Septiningsih et al. 2009) were susceptible to stagnant flooding (Vergara et al. 2014). The susceptibility of Sub1 lines was worse with varieties having short stature, as in the case of Swarna-Sub1-which was used as a susceptible check in our stagnant flooding stress phenotyping, showing very low survival by the end of the experiment. On the other hand, the tolerant check IRRI154 performed well, confirming our previous results (Kato et al. 2014). There is no significant difference of survival rates among Ciherang-Sub1 (69\%), IRRI154 (62\%), and IR10F365 (56\%) (Table 1). The grain yield under stagnant flooding was also higher for IRRI154 $\left(3,394 \mathrm{~kg} \mathrm{ha}^{-1}\right)$ and Ciherang-Sub1 (2,933 $\left.\mathrm{kg} \mathrm{ha}^{-1}\right)$, but 
Table 1 Descriptive statistics of each trait in the mapping population, parents, and checks under stagnant flooding

\begin{tabular}{|c|c|c|c|c|c|c|c|c|c|c|}
\hline Traits $^{a)}$ & Ciherang-Sub1 & IR10F365 & IRRI154 & Swarna-Sub1 & Population Mean & Highest line & Lowest line & LSD .05 & $\mathrm{H}^{2 \mathrm{~b})}$ & $p^{c)}$ \\
\hline DTF (d) & 96 & 104 & 104 & 117 & 96 & 107 & 88 & 4.20 & 0.88 & $* * *$ \\
\hline $\mathrm{PH}(\mathrm{cm})$ & 122.8 & 118.2 & 123.9 & 57.0 & 129.3 & 154.7 & 94.6 & 19.00 & 0.62 & $* * *$ \\
\hline TN & 5 & 7 & 10 & 4 & 7 & 11 & 4 & 3.40 & 0.21 & ns \\
\hline PN & 5 & 6 & 10 & 4 & 6 & 11 & 4 & 3.20 & 0.33 & $* *$ \\
\hline FLL (cm) & 27.5 & 30.8 & 40.4 & 12.7 & 29.6 & 38.6 & 22.0 & 7.40 & 0.5 & $* * *$ \\
\hline FLW (cm) & 1.9 & 1.6 & 1.8 & 0.9 & 1.8 & 2.1 & 1.5 & 0.28 & 0.4 & *** \\
\hline $\mathrm{PL}(\mathrm{cm})$ & 25.2 & 27.6 & 25.8 & 12.2 & 25.5 & 29.7 & 20.0 & 4.26 & 0.45 & $* * *$ \\
\hline $\mathrm{BM}\left(\mathrm{g} / \mathrm{m}^{2}\right)$ & 768.5 & 853.7 & 1230.8 & 520.5 & 985.0 & 1544.7 & 513.2 & 527.80 & 0.18 & ns \\
\hline $\mathrm{SER}(\mathrm{cm} / \mathrm{d})$ & 1.2 & 1.2 & 1.4 & 0.6 & 1.3 & 1.8 & 0.8 & 0.28 & 0.73 & $* * *$ \\
\hline $\mathrm{HI}$ & 0.36 & 0.14 & 0.29 & 0.01 & 0.28 & 0.56 & 0.10 & 0.20 & 0.39 & $* *$ \\
\hline GW (g) & 2.8 & 2.5 & 2.4 & 0.7 & 2.7 & 3.2 & 1.6 & 0.28 & 0.85 & $* * *$ \\
\hline $\mathrm{LSL}_{1}(\mathrm{~cm})$ & 12.6 & 13.8 & 11.0 & 3.2 & 14.2 & 24.4 & 9.2 & 4.40 & 0.45 & $* * *$ \\
\hline $\mathrm{LSL}_{2}(\mathrm{~cm})$ & 15.2 & 17.8 & 13.1 & 6.4 & 17.4 & 24.0 & 12.0 & 5.60 & 0.45 & $* *$ \\
\hline $\mathrm{LSL}_{3}(\mathrm{~cm})$ & 29.2 & 21.7 & 29.7 & 13.4 & 27.9 & 35.4 & 17.8 & 7.40 & 0.43 & $* * *$ \\
\hline GY (kg/Ha) & 2933 & 1246 & 3394 & 154 & 2685 & 5184 & 49 & 1543.80 & 0.64 & $* * *$ \\
\hline SR (\%) & 69 & 56 & 62 & 1 & 68 & 89 & 40 & 27.40 & 0.22 & * \\
\hline
\end{tabular}

${ }^{a)} D T F$ days to flowering, $P H$ plant height, $T N$ number of tillers, $P N$ number of panicles, FLL flag leaf length, FLW flag leaf width, $P L$ panicle length, $B M$ shoot biomass, SER shoot elongation rate, $H I$ harvest index, $G W 100$ grain weight, $L S L_{1}, L S L_{2}$, and $L S L_{3}$, respectively leaf sheath length for the first, second and third internodes, $G Y$ grain yield per plot, and SR survival rate

b) Heritability

c) ns: non significant; *significant at $P \leq 0.05$; ${ }^{* *}$ significant at $P \leq 0.01 ;{ }^{* * *}$ significant at $P \leq 0.001$

significantly lower for IR10F365 $\left(1,246 \mathrm{~kg} \mathrm{ha}^{-1}\right)$ and much lower for Swarna-Sub1 $\left(154 \mathrm{~kg} \mathrm{ha}^{-1}\right)$. The yield reduction of Ciherang-Sub1 under SF compared to the control was comparable to that of IRRI154 (49.5 vs. 51.3\%). In addition, Ciherang-Sub1 matured 5 days earlier under non-stress and 8 days earlier under stress compared with IRRI154 and IR10F365 (Tables 1 and 2). Under non-stress conditions, Ciherang-Sub1 had similar numbers of tillers and panicles compared to IRRI154 and IR10F365; while Swarna-Sub1 had a higher number of tillers and panicles. However, under stress tiller number and panicles of both Ciherang-Sub1 and IR10F365 was significantly reduced compared to IRRI154. Likewise, Ciherang-Sub1 and IR10F365 biomass was significantly affected under the stress (reduced by 40.9 and $40.7 \%$, respectively), while IRRI154 biomass was hardly affected and Swarna-Sub1 was severely affected (reduced by $71.1 \%$ ). It was also observed that IRRI154 had the highest shoot elongation rate under stress among the four varieties used in this study. The trend was also demonstrated in our earlier finding in which IRRI154 had the least biomass reduction and the fastest elongation compared with the other four varieties used in the study, including another tolerant check, IRRI119 or PSB Rc68 (Kato et al. 2014).

The current study showed that even though CiherangSub1 elongation was less than that of IRRI154 (4.0 vs. 9.8\%) and its biomass reduction was more affected compared to IRRI154, Ciherang-Sub1 had better tolerance to stagnant flooding compared to the first generation of Sub1 lines, which were the first six Sub1 lines developed by IRRI (Vergara et al. 2014). The good performance of Ciherang-Sub1 could partly be the result of its intermediate height $(118.1 \mathrm{~cm})$, which was similar to IR10F365 $(122.8 \mathrm{~cm})$, slightly taller than IRRI154 $(112.8 \mathrm{~cm})$ and significantly taller than Swarna-Sub1 $(106 \mathrm{~cm})$ under control condition. While under stagnant flooding its height $(122.8 \mathrm{~cm})$ was similar to IRRI154 $(123.9 \mathrm{~cm})$ and IR10F365 $(118.2 \mathrm{~cm})$, but significantly taller than that of Swarna-Sub1 $(57 \mathrm{~cm})$. Shoot elongation rate of Ciherang-Sub1 $(1.2 \mathrm{~cm} / \mathrm{d})$ was similar to IR10F365 $(1.2 \mathrm{~cm} / \mathrm{d})$ and IRRI154 $(1.4 \mathrm{~cm} / \mathrm{d})$, but significantly faster than that of Swarna-Sub1 $(0.6 \mathrm{~cm} / \mathrm{d})$. As shown in our previous study, IRRI154 tolerance was mostly due to its medium elongation rate, which enabled its canopy to keep up with the water surface (Kato et al. 2014). In summary, the advantage of Ciherang-Sub1 under stagnant flooding is its partial elongation and inherent intermediate height.

IR10F365, a breeding line from IRRI's submergence breeding team, has consistently shown strong submergence and stagnant flooding tolerance in field trials. This line has also performed well in trials from the National Coordinated Trials of the Philippines in flood-prone areas. In our current study, however, IR10F365 slightly underperformed compared to Ciherang-Sub1 in both control and stagnant flooding. This might be due to the 
Table 2 Descriptive statistics of each trait in the mapping population, parents, and checks under irrigated control condition

\begin{tabular}{|c|c|c|c|c|c|c|c|c|c|c|}
\hline Traits $^{a)}$ & Ciherang-Sub1 & IR10F365 & IRRI154 & Swarna-Sub1 & Population Mean & Highest line & Lowest line & LSD .05 & $\mathrm{H}^{2 \mathrm{~b})}$ & $p^{c)}$ \\
\hline$\overline{\text { DTF }(d)}$ & 87 & 92 & 92 & 106 & 89 & 96 & 80 & 2.81 & 0.95 & $* * *$ \\
\hline $\mathrm{PH}(\mathrm{cm})$ & 118.1 & 122.8 & 112.8 & 109.0 & 125.3 & 139.3 & 99.92 & 8.32 & 0.88 & $* * *$ \\
\hline TN & 10 & 11 & 12 & 16 & 10 & 13 & 7 & 2.68 & 0.54 & $* * *$ \\
\hline PN & 10 & 11 & 11 & 16 & 10 & 18 & 7 & 3.41 & 0.32 & $*$ \\
\hline FLL (cm) & 29.5 & 38.0 & 36.4 & 26.3 & 32.0 & 43.09 & 23.91 & 6.57 & 0.61 & $* * *$ \\
\hline FLW (cm) & 2.1 & 1.8 & 1.7 & 1.9 & 1.9 & 2.35 & 1.54 & 0.31 & 0.53 & $* * *$ \\
\hline $\mathrm{PL}(\mathrm{cm})$ & 25.01 & 25.99 & 23.46 & 23.49 & 26.09 & 30.5 & 21.54 & 2.22 & 0.78 & $* * *$ \\
\hline $\mathrm{BM}\left(\mathrm{g} / \mathrm{m}^{2}\right)$ & 1301.33 & 1438.67 & 1262.24 & 1803.67 & 1329.34 & 1762.8 & 757.2 & 399 & 0.25 & * \\
\hline $\operatorname{SER}(\mathrm{cm} / \mathrm{d})$ & 1.4 & 1.1 & 1.3 & 1.0 & 1.3 & 1.8 & 0.9 & 0.31 & 0.55 & $* * *$ \\
\hline $\mathrm{HI}$ & 0.45 & 0.31 & 0.56 & 0.18 & 0.43 & 0.6 & 0.22 & 0.16 & 0.45 & $* *$ \\
\hline GW (g) & 2.7 & 2.4 & 2.4 & 2.0 & 2.7 & 3.12 & 2.39 & 0.17 & 0.89 & $* * *$ \\
\hline $\mathrm{LSL}_{1}(\mathrm{~cm})$ & 9.8 & 14.0 & 11.9 & 11.0 & 14.1 & 23.96 & 5.65 & 4.73 & 0.55 & $* * *$ \\
\hline $\mathrm{LSL}_{2}(\mathrm{~cm})$ & 20.3 & 20.0 & 18.4 & 17.0 & 22.1 & 28.1 & 12.6 & 4.82 & 0.53 & $* * *$ \\
\hline $\mathrm{LSL}_{3}(\mathrm{~cm})$ & 35.1 & 30.9 & 31.1 & 27.3 & 32.7 & 41.16 & 25 & 5.08 & 0.74 & $* * *$ \\
\hline GY (kg/Ha) & 5809 & 4680 & 6974 & 3391 & 5605 & 7398 & 3600 & 1322.80 & 0.59 & $* * *$ \\
\hline
\end{tabular}

${ }^{\text {a) } D T F}$ days to flowering, $P H$ plant height, $T N$ number of tillers, $P N$ number of panicles, $F L L$ flag leaf length, $F L W$ flag leaf width, $P L$ panicle length, $B M$ shoot biomass, SER shoot elongation rate, $H$ l harvest index, GW 100 grain weight, $L S L_{1}, L S L_{2}$, and $L S L_{3}$, respectively leaf sheath length for the first, second and third internodes, and GY grain yield per plot

b) Heritability

c)ns: non significant; *significant at $P \leq 0.05 ;{ }^{* *}$ significant at $P \leq 0.01 ;{ }^{* * *}$ significant at $P \leq 0.001$

use of older seed stock of this particular line (due to unavailability of fresh seeds from the same batch) which may have caused a slower rate of germination and growth, which subsequently affected yield. For our mapping population, however, other than the parental lines we also included the susceptible check Swarna-Sub1 and the tolerant check IRRI154 which can also be used as negative and positive checks, respectively, when we investigate the performance of the selected individuals in the mapping population.

\section{Mapping population performance under stagnant flooding vs. control conditions}

The mean grain yield (GY) of the population decreased significantly, by $52.1 \%$ under SF (Tables 1 and 2 ). Kato et al. (2014) reported similar results where yield under stress was reduced by $47 \%$ across genotypes. The best performing line under SF (RIL-214) yielded $5,184 \mathrm{~kg} \mathrm{ha}^{-1}$ with a yield advantage of $43.5 \%$ over Ciherang-Sub1 and $34.5 \%$ over the best tolerant check, IRRI154. The large yield increase under stress, however, was not reflected under irrigated conditions since the yield of the same was $5,676 \mathrm{~kg} \mathrm{ha}^{-1}$ under control conditions compared to the most productive line (RIL-186) at $7,398 \mathrm{~kg} \mathrm{ha}^{-1}$ (Additional file 2: Table S2). However, RIL-186 yield was only $2,584 \mathrm{~kg} \mathrm{ha}^{-1}$ under SF, suggesting that this line is less tolerant. Interestingly, the sixth best line under SF was also at the same rank under control conditions, with grain yield of 4,067 and $6,681 \mathrm{~kg} \mathrm{ha}^{-1}$, respectively. Therefore, it is possible to develop high-yielding lines that thrive in both environments out of this population, even though they might not be the best performers in either environment. Likewise, the tolerant check IRRI154 performs well in both control and SF conditions, but the downside of this variety is its low grain quality and sensitivity to complete submergence. The worst performer under SF only yielded $921 \mathrm{~kg} \mathrm{ha}^{-1}$. Compared to this line, the best performer under stress was $24.0 \%$ taller, had more than double its biomass, with $44 \%$ faster rate of shoot elongation and had more than triple harvest index. It was worth noting that under SF, 26 RILs yielded higher than IRRI154 and 60 RILs yielded higher than Ciherang-Sub1. Under control conditions, only one line has higher yield than IRRI154, while 66 lines were better than Ciherang-Sub1 (data not shown). For 100 grain weight $(\mathrm{GW})$, the mean of the population in both conditions was unchanged (Tables 1 and 2). The averages biomass (BM) and harvest index (HI) of the population were reduced by 25.9 and $34.9 \%$ under stress, respectively. Among these traits, heritability $\left(\mathrm{H}^{2}\right)$ was highest for grain weight in both stress and control conditions (0.85 vs. 0.89$)$, while heritability for grain yield was moderate (0.64 vs. 0.59 ), and low for HI and BM.

The mean of plant height $(\mathrm{PH})$ under $\mathrm{SF}$ similar is similar compared to the control (only 3.4\% increased); while the mean shoot elongation rate (SER) stayed the same under both environments (Tables 1 and 2). Under SF, mean days to flowering (DTF) was 96 days, which was equal to that of Ciherang-Sub1 but earlier than 
IR10F365 and IRRI154 by 8 days and Swarna-Sub1 by 21 days. The mean of DTF under control condition was 89 days, which was not significantly difference compared to those of Ciherang-Sub1, IR10F365 and IRRI154, but 17 days earlier than Swarna-Sub1. The overall mean delay caused by SF across the mapping population was 7 days. It was previously reported that stagnant flooding delays flowering.

Under SF, tillers and panicle number were reduced by 30 and $40 \%$, respectively, compared to the control, which was similar to that of IR10F365 and CiherangSub1 (Tables 1 and 2). Interestingly, the average panicle length of the mapping population, along with those of Ciherang-Sub1, IR10F365, and IRRI154 were hardly affected. Likewise, the population averages of flag leaf length (FLL) and flag leaf width (FLW) were only slightly reduced. Average leaf sheath length for the $1^{\text {st }}$ internode $\left(\mathrm{LSL}_{1}\right)$ of the mapping population was less affected; however, average leaf sheath length for the $2^{\text {nd }}$ and $3^{\text {rd }}$ internodes $\left(\mathrm{LSL}_{2}\right.$ and $\left.\mathrm{LSL}_{3}\right)$ of the population were reduced by 21.3 and $15.3 \%$, respectively. This trend was similar to those of the parents and checks, with SwarnaSub1 being the most affected. Overall, the population has high mean of survival rate under SF, ranging from 40 to $89 \%$, with an average of $68 \%$, which was similar to that of Ciherang-Sub1 (69\%).

To investigate the effect of individual traits on yield stability across stagnant flooding and irrigated conditions, the percentage difference for each trait was calculated for the 25 highest and 25 lowest yielding lines under SF and the control (Additional file 3: Figure S1 and Additional file 4: Figure S2). Under SF, the two traits with biggest differences were $\mathrm{GY}$ and $\mathrm{HI}$; this was followed by moderate differences in PN, BM, SER, SR, all LSL, TN, PH, and FLL. These traits largely contribute to higher $\mathrm{HI}$ and yield. Under control condition, the two largest contrasting traits were also GY and HI, even though the differences were smaller compared to those under stress. It was also shown that the lines with higher shoot elongation rate had higher survival rate but not all performed well. The lines having elongation rate between 1.2 and $1.6 \%$ were high yielding and had good survival rate of $60-80 \%$ (Additional file 5: Figure S3). This was likely due to high carbohydrate consumption in fast-elongating lines to avoid complete submergence, but at the expense of yield. However, moderate SER was strongly and positively correlated with grain yield under stress, as previously reported (Kato et al. 2014; Vergara et al. 2014).

\section{Correlation among traits}

Under stagnant flooding, grain yield of the mapping population correlated positively with all the traits, except DTF. Traits having very highly significant correlation
(*****; $p$-value $\leq 0.001)$ with GY were HI (0.70), PH (0.58), SER (0.44), BM (0.43), $\mathrm{LSL}_{3}(0.43), \mathrm{FLW}(0.40)$ and $\mathrm{LSL}_{1}$ (0.40), $\mathrm{LSL}_{2}$ (0.40), PN (0.36), PL (0.31), FLL (0.29), and GW (0.29); while TN (0.25) had highly significant correlation ( ${ }^{* * ;} ; p$-value $\leq 0.01$; Additional file 6: Table S3). Survival rate was correlated with all the traits, except HI. Traits having very highly significant correlation with SR were PH (0.61), BM (0.47), GW (0.47), $\mathrm{LSL}_{2}$ (0.43), PL (0.42), FLW (0.41), $\mathrm{LSL}_{1}(0.40), \mathrm{LSL}_{3}$ (0.39), SER (0.39), PN (0.38), and FLL (0.30); while traits having highly significant correlation were TN $(0.25)$ and DTF $(-0.24)$. All LSS traits were positively very highly significant correlation with PH and SER, but negatively very highly significant correlation with DTF (Additional file 6: Table S3). Under SF, all traits were correlated with plant height. Traits having very highly significant correlation with $\mathrm{PH}$ were $\mathrm{LSL}_{2}$ (0.72), BM (0.67), $\mathrm{LSL}_{1}(0.63)$, SER (0.62), SR (0.61), GW (0.59), PL (0.59), GY (0.58), $\mathrm{LSL}_{3}$ (0.55), FLW (0.54), FLL (0.37), and PN (0.28); while traits having highly significant correlation were TN $(0.24)$ and DTF $(-0.24)$, and trait having significant correlation $(* ; p$-value $\leq 0.05)$ was $\mathrm{HI}(0.18)$. Additionally, DTF were negatively very highly significant correlation with SER $(-0.56), \mathrm{LSL}_{1-3}(-0.41,-0.41,-0.42$, respectively), and FLL (-0.33); while it was negatively highly significant correlated with SR (-0.24) and PH (-0.24), and negatively significant correlated with $\mathrm{HI}(-0.21)$, FLW $(-0.21)$ and TN $(-0.16)$.

In general, the correlations among traits were weaker under control conditions than under SF. Under control conditions, the only trait that was very highly significant correlated $(* * *)$ with GY was HI $(0.71)$; it was also highly significantly correlated $(* *)$ with $\mathrm{LSL}_{2}(0.25)$ and DTF $(-0.25)$, and significantly correlated (*) with SER (0.17) (Additional file 7: Table S4). All LSL were very highly significantly correlated with $\mathrm{PH}$. Under control conditions, DTF had either positive or negative correlation with some of the traits (Additional file 7: Table S4).

\section{Identification of QTLs}

Out of 4606 high quality SNP markers on the $6 \mathrm{~K} \mathrm{SNP}$ chip, $10 \%$ (469) were polymorphic between CiherangSub1 and IR10F365. The rice physical map of Nipponbare (MSU v.7) was used to order the markers. The marker distances were calculated from the genotype data using MapManager QTX vQTXb20 (Manly et al. 2001) and had a total length of 1,250.4 cM with an average of 2.74 cM between markers. QTL analysis using both QTL Cartographer and QGene identified a total of 38 and 46 QTLs under stagnant flooding and the control, respectively (Tables 3 and 4; Figs. 1 and 2). There were 16 QTLs detected in both environments; in addition several QTL clusters were observed. Under SF, QTLs were detected from 13 out of 16 traits (except PN, TN, and BM), while under control, QTLs were detected from all 15 
Table 3 QTLs for yield in agronomic traits from a RIL population of Ciherang-Sub1/IR10F365 identified under stagnant flooding condition

\begin{tabular}{|c|c|c|c|c|c|c|c|c|c|c|c|c|c|c|c|c|}
\hline \multirow[t]{2}{*}{ Trait } & \multirow[t]{2}{*}{ QTL } & \multirow[t]{2}{*}{ Chr } & \multirow[t]{2}{*}{ Flanking markers } & \multirow[t]{2}{*}{ Source ${ }^{b)}$} & \multicolumn{3}{|c|}{ QTL Cart. CIM } & \multicolumn{3}{|c|}{ QTL Cart. IM ${ }^{\mathrm{C})}$} & \multicolumn{3}{|c|}{ QGENE CIM } & \multicolumn{3}{|c|}{ QGENE IM } \\
\hline & & & & & LOD & $R^{2}$ & Add & $\overline{L O D}$ & $\mathrm{R}^{2}$ & Add & $\overline{L O D}$ & $R^{2}$ & Add & LOD & $R^{2}$ & Add \\
\hline \multirow[t]{6}{*}{ GW } & q GW1.1 & 1 & 214137-id1007975 & C & $\underline{4.36}$ & 8.7 & -0.06 & 4.21 & 12.3 & -0.07 & 3.35 & 10.0 & $\underline{0.05}$ & 3.24 & 10.0 & 0.07 \\
\hline & q GW2.1 & 2 & id2004418-1845605 & C & & & & 2.70 & 8.0 & -0.05 & & & & & & \\
\hline & q GW3.1 & 3 & 2499734-id3002805 & C & & & & 2.80 & 10.2 & -0.06 & & & & & & \\
\hline & qGW5.1 & 5 & 5428382-ud5000983 & C & $\underline{4.07}$ & $\underline{8.3}$ & -0.06 & $\underline{3.80}$ & $\underline{11.0}$ & -0.06 & $\underline{3.73}$ & $\underline{11.0}$ & $\underline{0.08}$ & $\underline{4.17}$ & $\underline{12.0}$ & $\underline{0.07}$ \\
\hline & qGW10.1 & 10 & $10603169-10703329$ & । & $\underline{6.30}$ & 13.1 & $\underline{0.07}$ & 3.15 & 10.0 & 0.06 & & & & & & \\
\hline & $q G W 10.2$ & 10 & 9958372-id10003608 & C & $\underline{4.14}$ & $\underline{9.0}$ & -0.06 & & & & $\underline{3.41}$ & $\underline{10.0}$ & -0.07 & 2.50 & 8.0 & -0.06 \\
\hline \multirow[t]{5}{*}{ DTF } & qDTF1.1 & 1 & 801364-id1016674 & । & $\underline{3.08}$ & $\underline{6.0}$ & $\underline{0.88}$ & 2.78 & 8.2 & 1.03 & 3.40 & 10.0 & -0.89 & & & \\
\hline & qDTF3.1 & 3 & 2499734-2560888 & C & $\underline{12.50}$ & $\underline{26.0}$ & -1.80 & $\underline{6.81}$ & 20.0 & -1.57 & $\underline{5.43}$ & 16.0 & 1.20 & $\underline{6.00}$ & $\underline{17.0}$ & 1.49 \\
\hline & qDTF5.1 & 5 & 5515384-id5013231 & C & $\underline{4.11}$ & $\underline{7.0}$ & -1.01 & 3.17 & 9.3 & -1.13 & 3.65 & 11.0 & 1.27 & $\underline{3.63}$ & $\underline{11.0}$ & $\underline{1.23}$ \\
\hline & qDTF6.1 & 6 & id6015097-6906738 & । & & & & $\underline{3.95}$ & 12.0 & 1.54 & & & & $\underline{4.37}$ & 13.0 & -1.73 \\
\hline & qDTF10.1 & 10 & id10002842-10586997 & I & $\underline{5.22}$ & $\underline{9.0}$ & 1.07 & 3.01 & 9.0 & 1.04 & 2.68 & 8.0 & -0.82 & & & \\
\hline \multirow[t]{2}{*}{ FLW } & qFLW3.1 & 3 & 2499734-2560888 & C & $\underline{4.00}$ & 11.3 & -0.04 & 3.47 & 11.0 & -0.04 & & & & 3.22 & 10.0 & 0.04 \\
\hline & qFLW7.1 & 7 & 7869914-7949610 & C & & & & 3.11 & 14.0 & -0.04 & & & & & & \\
\hline \multirow[t]{4}{*}{ FLL } & qFLL4.1 & 4 & id4000574-4295290 & I & $\underline{4.11}$ & $\underline{9.3}$ & $\underline{1.10}$ & $\underline{2.78}$ & $\underline{8.2}$ & $\underline{1.03}$ & $\underline{3.79}$ & $\underline{11.1}$ & -1.12 & 2.87 & 8.5 & -1.08 \\
\hline & qFLL5.1 & 5 & ud5000983-5747652 & 1 & $\underline{6.18}$ & 14.0 & $\underline{1.36}$ & $\underline{3.69}$ & $\underline{11.0}$ & $\underline{1.17}$ & & & & $\underline{3.53}$ & $\underline{10.4}$ & -1.18 \\
\hline & qFLL6.1 & 6 & 6887046-6906738 & C & & & & 2.71 & 8.5 & -1.28 & & & & 2.98 & 8.9 & 1.42 \\
\hline & qFLL9.1 & 9 & 9592671-id9007287 & । & $\underline{2.94}$ & $\underline{13.0}$ & $\underline{1.23}$ & & & & 2.99 & 8.9 & -1.65 & 2.60 & 7.8 & -1.85 \\
\hline \multirow[t]{3}{*}{ GY } & $9 G Y 3.1$ & 3 & 2499734-2560888 & C & $\underline{6.20}$ & 14.3 & -321.60 & 2.83 & 9.0 & -246.10 & 2.64 & 8.0 & 224.3 & $\underline{2.84}$ & $\underline{8.4}$ & 250.46 \\
\hline & $9 G Y 5.1$ & 5 & id5003312-ud5000983 & I & $\underline{3.66}$ & 12.2 & 301.7 & & & & 2.15 & 7.0 & -190.7 & & & \\
\hline & qGY6.1 & 6 & id6000402-5903052 & C & $\underline{3.46}$ & $\underline{7.4}$ & -282.1 & & & & 3.04 & 9.0 & 263.8 & & & \\
\hline \multirow[t]{4}{*}{$\mathrm{HI}$} & $9 H 12.1$ & 2 & 1489783-1845605 & 1 & 3.41 & 72.4 & 0.03 & & & & 2.18 & 6.6 & -0.02 & & & \\
\hline & qHI5.1 & 5 & id5003312-5515384 & । & 3.34 & 72 & 0.03 & & & & & & & & & \\
\hline & qHI7.1 & 7 & 7768382-7949610 & C & $\underline{8.67}$ & $\underline{20.4}$ & $\underline{-0.05}$ & $\underline{3.64}$ & $\underline{10.6}$ & $\underline{-0.03}$ & $\underline{7.07}$ & 19.7 & $\underline{0.05}$ & $\underline{3.80}$ & 11.1 & $\underline{0.03}$ \\
\hline & qHI7.2 & 7 & 7102234-id7002749 & । & $\underline{4.65}$ & $\underline{10}$ & $\underline{0.03}$ & & & & & & & & & \\
\hline $\mathrm{LSL}_{1}$ & $q L S L_{1} 5.1$ & 5 & ud5000983-5747652 & I & $\underline{4.40}$ & 11.0 & $\underline{0.74}$ & $\underline{4.00}$ & 12.0 & $\underline{0.76}$ & & & & $\underline{4.04}$ & $\underline{12.0}$ & -0.79 \\
\hline \multirow[t]{2}{*}{$\mathrm{LSL}_{2}$} & $q L S L_{2} 5.1$ & 5 & ud5000983-5747652 & 1 & $\underline{4.73}$ & 10.2 & 0.82 & $\underline{4.86}$ & 15.0 & $\underline{0.96}$ & 2.57 & 7.7 & -0.82 & $\underline{4.96}$ & $\underline{14.3}$ & -0.98 \\
\hline & $q L S L_{2} 6.1$ & 6 & $6228054-6585321$ & । & $\underline{4.10}$ & $\underline{9.0}$ & $\underline{0.91}$ & & & & & & & $\underline{3.66}$ & $\underline{11.0}$ & -1.38 \\
\hline \multirow[t]{2}{*}{$\mathrm{LSL}_{3}$} & $q L S L_{3} 2.1$ & 2 & 1529216-1845605 & C & $\underline{4.16}$ & 10.0 & -1.06 & 2.99 & 9.0 & -1.00 & 2.37 & 7.1 & 0.85 & 2.78 & 8.3 & 0.97 \\
\hline & $q L S L_{3} 5.1$ & 5 & $5515384-5747652$ & । & $\underline{3.49}$ & $\underline{8.0}$ & $\underline{1.00}$ & 2.72 & 9.0 & 1.04 & & & & 3.17 & 9.4 & 1.11 \\
\hline \multirow[t]{2}{*}{ SER } & qSER5.1 & 5 & ud5000983-id5013231 & । & 12.5 & $\underline{32.0}$ & $\underline{0.11}$ & $\underline{8.63}$ & 24.0 & $\underline{0.09}$ & $\underline{4.12}$ & 12.0 & -0.06 & $\underline{9.20}$ & $\underline{24.9}$ & -0.10 \\
\hline & qSER6.1 & 6 & 6619487-6816224 & C & 3.05 & 6.0 & -0.05 & 2.82 & 8.3 & -0.06 & $\underline{3.79}$ & $\underline{11.1}$ & $\underline{0.05}$ & $\underline{2.87}$ & $\underline{8.5}$ & $\underline{0.06}$ \\
\hline \multirow[t]{3}{*}{$\mathrm{PH}$} & qPH3.1 & 3 & 2499734-2560888 & C & $\underline{4.04}$ & 8.3 & -2.77 & 3.10 & 9.4 & -2.88 & 3.34 & 10.0 & 2.67 & 2.57 & 8.00 & 2.69 \\
\hline & qPH5.1 & 5 & ud5000983-5747652 & । & $\underline{5.59}$ & 12.1 & $\underline{3.45}$ & $\underline{4.73}$ & 14.0 & $\underline{3.65}$ & & & & $\underline{4.97}$ & $\underline{14.3}$ & -3.81 \\
\hline & qPH6.1 & 6 & $6228054-6585321$ & । & & & & & & & 3.40 & 10.0 & -3.74 & & & \\
\hline \multirow[t]{2}{*}{$P L$} & qPL7.1 & 7 & id7004922-7949610 & 1 & 3.21 & 11.2 & 0.61 & & & & & & & & & \\
\hline & QPL9.1 & 9 & $9641863-9869869$ & । & $\underline{5.47}$ & $\underline{22.0}$ & $\underline{0.82}$ & $\underline{4.42}$ & $\underline{21.2}$ & $\underline{0.81}$ & 3.29 & 10.0 & -0.53 & $\underline{3.64}$ & 11.0 & -0.61 \\
\hline \multirow[t]{2}{*}{ SR } & qSR1.1 & 1 & 20215-id1001821 & I & 2.89 & 10.0 & 3.18 & & & & 2.63 & 8.0 & -2.77 & & & \\
\hline & qSR6.1 & 6 & id6008688-6766627 & C & 2.97 & 7.3 & -2.99 & & & & 2.50 & 7.4 & 4.01 & & & \\
\hline
\end{tabular}

${ }^{a)} D T F$ days to flowering, $F L W$ flag leaf width, $F L L$ flag leaf length, $G Y$ grain yield per plot, $H I$ harvest index, $L S L_{1}, L S L_{2}$, and $L S L_{3}$, respectively leaf sheath length for the first, second and third internodes, SER shoot elongation rate, $P H$ plant height, $P L$ panicle length, and SR survival rate

${ }^{\text {b) }}$ : Ciherang-Sub1; I: IR10F365

c) underlined and bold numbers: significant at $P \leq 0.01$; bold numbers: significant at $P \leq 0.05$; italic: not significant but with LOD $\geq 2.0$ 
Table 4 QTLs for yield in agronomic traits from a RIL population of Ciherang-Sub1/R10F365 identified under irrigated control condition

\begin{tabular}{|c|c|c|c|c|c|c|c|c|c|c|c|c|c|c|c|c|}
\hline \multirow[t]{2}{*}{ Trait } & \multirow[t]{2}{*}{ QTL } & \multirow[t]{2}{*}{ Chr } & \multirow[t]{2}{*}{ Flanking markers } & \multirow[t]{2}{*}{ Source } & \multicolumn{3}{|c|}{ QTL Cart. CIM } & \multicolumn{3}{|c|}{ QTL Cart. IM } & \multicolumn{3}{|c|}{ QGENE CIM } & \multicolumn{3}{|c|}{ QGENE IM } \\
\hline & & & & & LOD & $R^{2}$ & Add & LOD & $R^{2}$ & Add & LOD & $R^{2}$ & Add & LOD & $R^{2}$ & Add \\
\hline \multirow[t]{4}{*}{ GW } & qGW1.1 & 1 & 214137-id1007975 & $C$ & 4.74 & 11.4 & -0.05 & 5.34 & 15.2 & -0.05 & $\underline{4.40}$ & 12.8 & 0.06 & 4.35 & 12.7 & 0.05 \\
\hline & qGW2.1 & 2 & 1661393-1981019 & C & 3.29 & 6.5 & -0.04 & $\underline{4.21}$ & 12.2 & -0.05 & 3.13 & 9.3 & 0.04 & 3.14 & 9.3 & 0.04 \\
\hline & qGW2.1 & 2 & $2153125-2422788$ & C & & & & & & & 2.74 & 8.2 & -0.04 & & & \\
\hline & qGW5.1 & 5 & 5428382-ud5000983 & C & 2.39 & 5.0 & -0.03 & 3.60 & 10.5 & -0.04 & 2.51 & 7.5 & 0.04 & 3.13 & 9.3 & 0.04 \\
\hline \multirow[t]{3}{*}{ DTF } & qDTF3.1 & 3 & 2499734-2519460 & C & $\underline{21.81}$ & 42.2 & -2.44 & 13.53 & 34.9 & -2.20 & 17.36 & 41.7 & $\underline{2.35}$ & 13.14 & $\underline{33.6}$ & $\underline{2.22}$ \\
\hline & qDTF6.1 & 6 & id6015421-6906738 & । & & & & $\underline{4.09}$ & 11.9 & $\underline{1.70}$ & & & & $\underline{3.70}$ & $\underline{10.9}$ & $\underline{-1.70}$ \\
\hline & qDTF10.1 & 10 & id10003608-10579252 & । & 5.70 & 9.0 & 1.13 & 2.99 & 8.8 & 1.11 & 5.43 & 15.5 & -1.18 & & & \\
\hline \multirow[t]{5}{*}{ FLW } & qFLW3.1 & 3 & 2499734-2519460 & C & $\underline{5.18}$ & 11.0 & $\underline{-0.05}$ & & & & 3.49 & 10.3 & $\underline{0.10}$ & & & \\
\hline & qFLW4.1 & 4 & $4683923-4728960$ & C & 8.88 & $\underline{20.1}$ & -0.09 & 3.73 & 10.9 & -0.06 & 3.98 & $\underline{11.6}$ & 0.06 & 3.29 & 9.7 & 0.06 \\
\hline & qFLW5.1 & 5 & id5001564-id5003312 & C & 2.67 & 5.4 & -0.04 & & & & & & & 2.72 & 8.1 & -0.05 \\
\hline & qFLW12.1 & 12 & c12p5738988-id12005832 & । & $\underline{4.80}$ & $\underline{10.3}$ & $\underline{0.06}$ & & & & & & & & & \\
\hline & qFLW12.2 & 12 & $12740505-12939027$ & C & $\underline{3.44}$ & $\underline{7.3}$ & -0.05 & & & & & & & & & \\
\hline \multirow[t]{4}{*}{ FLL } & qFLL1.1 & 1 & id1016971-1305247 & C & 3.81 & 25.2 & -1.79 & & & & & & & & & \\
\hline & qFLL2.1 & 2 & 1543608-1902547 & । & 3.00 & 6.8 & 0.96 & 2.97 & 8.8 & 1.06 & $\underline{3.85}$ & $\underline{11.3}$ & -1.19 & $\underline{3.54}$ & $\underline{10.4}$ & $\underline{-1.17}$ \\
\hline & qFLL4.1 & 4 & id4002348-4253547 & । & 3.05 & 6.8 & 0.99 & & & & 3.15 & 9.3 & -1.15 & & & \\
\hline & qFLL5.1 & 5 & 5719825-5747652 & । & 3.90 & $\underline{9.1}$ & $\underline{1.12}$ & & & & & & & & & \\
\hline GY & qGY12.1 & 12 & $12648838-12931835$ & । & 3.39 & 9.2 & 247.20 & & & & 2.27 & 6.8 & -206.30 & & & \\
\hline \multirow[t]{2}{*}{$\mathrm{HI}$} & qHI3.1 & 3 & 2499734-2560888 & । & 3.50 & 8.0 & 0.02 & & & & $\underline{4.91}$ & 14.2 & -0.03 & 2.25 & 6.7 & -0.02 \\
\hline & qHI7.1 & 7 & id7002749-7730100 & C & & & & & & & 3.50 & 10.3 & 0.05 & & & \\
\hline \multirow[t]{3}{*}{$\mathrm{LSL}_{1}$} & $q L S L_{1} 1.1$ & 1 & 275443-id1007975 & C & 4.37 & 9.8 & -0.78 & 3.18 & 9.4 & -0.77 & & & & & & \\
\hline & $q L S L_{1} 3.1$ & 3 & $\mathrm{fd} 9-2519460$ & C & $\underline{5.33}$ & 13.1 & $\underline{0.93}$ & $\underline{3.78}$ & 11.0 & -0.82 & 3.95 & 11.6 & 0.83 & 3.23 & 9.6 & 0.76 \\
\hline & $q L S L, 5.1$ & 5 & ud5000983-5747652 & । & & & & $\underline{3.93}$ & 11.8 & 0.88 & 2.79 & 8.3 & -0.86 & $\underline{3.80}$ & $\underline{11.1}$ & $\underline{0.88}$ \\
\hline \multirow[t]{3}{*}{$\mathrm{LSL}_{2}$} & $q L S L_{2} 3.1$ & 3 & id3003846-3236543 & C & 3.70 & 8.1 & -0.67 & 2.59 & 7.8 & -0.65 & 3.23 & 9.6 & 0.94 & & & \\
\hline & $q L S L_{2} 5.1$ & 5 & 5515384-id5013231 & । & $\underline{4.95}$ & 11.2 & $\underline{0.84}$ & 2.77 & 9.4 & 0.76 & & & & 3.03 & 9.0 & -0.83 \\
\hline & $q L S L_{2} 9.1$ & 9 & 9592671-id9007287 & । & $\underline{4.33}$ & 16.8 & 0.97 & 2.84 & 17.6 & 0.99 & $\underline{4.45}$ & 12.9 & -1.59 & 3.29 & 9.7 & -1.45 \\
\hline \multirow[t]{6}{*}{$\mathrm{LSL}_{3}$} & $q L S L_{3} 2.1$ & 2 & 1562092-id2007797 & C & & & & $\underline{3.92}$ & 11.4 & -1.06 & $\underline{4.41}$ & 12.8 & $\underline{1.10}$ & $\underline{3.89}$ & 11.4 & 1.08 \\
\hline & $q L S L_{3} 3.1$ & 3 & 2573346-2610698 & C & 2.63 & 4.1 & -0.69 & $\underline{3.60}$ & 10.5 & -1.03 & $\underline{4.40}$ & 12.8 & $\underline{1.24}$ & 3.18 & 9.4 & 1.03 \\
\hline & $q L S L_{3} 5.1$ & 5 & ud5000983-5747652 & । & $\underline{6.73}$ & 12.8 & 1.17 & $\underline{2.96}$ & 10.2 & $\underline{1.03}$ & & & & 3.12 & 9.3 & -1.02 \\
\hline & $q L S L_{3} 6.1$ & 6 & 6619487-6816224 & C & $\underline{5.83}$ & 10.4 & -1.10 & & & & & & & & & \\
\hline & $q L S L_{3} 8.1$ & 8 & $8803052-9049928$ & । & 7.41 & 14.7 & $\underline{1.29}$ & $\underline{4.18}$ & 22.1 & 1.49 & $\underline{6.24}$ & 17.6 & -2.47 & $\underline{5.59}$ & $\underline{16.0}$ & $\underline{-2.38}$ \\
\hline & $q L S L_{3} 11.1$ & 11 & id11007523-11608239 & C & $\underline{5.22}$ & $\underline{9.3}$ & -0.95 & $\underline{3.40}$ & 10.0 & -0.97 & $\underline{4.03}$ & 11.8 & $\underline{1.19}$ & $\underline{3.69}$ & 10.9 & 1.05 \\
\hline \multirow[t]{2}{*}{ SER } & QSER5.1 & 5 & 5515384-id5013231 & । & 8.10 & $\underline{20.0}$ & $\underline{0.08}$ & $\underline{6.53}$ & $\underline{20.0}$ & $\underline{0.08}$ & 3.02 & 9.0 & -0.06 & 7.08 & $\underline{19.8}$ & $\underline{0.09}$ \\
\hline & qSER6.1 & 6 & 6585321-6816224 & C & $\underline{3.70}$ & $\underline{8.0}$ & -0.05 & & & & & & & & & \\
\hline \multirow[t]{3}{*}{$\mathrm{PH}$} & qPH1.1 & 1 & 197232-id1007975 & C & & & & 3.13 & 10.2 & -2.38 & & & & 2.55 & 7.6 & 2.09 \\
\hline & qPH3.1 & 3 & 2519460-id3002805 & C & $\underline{3.15}$ & $\underline{7.0}$ & -1.96 & & & & 3.12 & 9.3 & 2.31 & & & \\
\hline & qPH5.1 & 5 & ud5000983-5747652 & । & $\underline{9.90}$ & 23.9 & 3.71 & 8.22 & 22.4 & 3.57 & 3.98 & 11.7 & -2.99 & 7.62 & $\underline{21.1}$ & $\underline{-3.58}$ \\
\hline TN & aTN3.1 & 3 & 2519460-id3003846 & । & 3.31 & 9.3 & 0.41 & $\underline{3.85}$ & 11.7 & $\underline{0.45}$ & 3.64 & 10.7 & -0.49 & 4.29 & $\underline{12.5}$ & $\underline{-0.49}$ \\
\hline$P L$ & qPL1.1 & 1 & id1015390-id1016971 & C & $\underline{3.51}$ & $\underline{6.7}$ & -0.44 & & & & & & & & & \\
\hline & qPL2.1 & 2 & 1529216-1845605 & । & 7.11 & 14.3 & $\underline{0.66}$ & $\underline{4.66}$ & 13.4 & $\underline{0.60}$ & $\underline{4.80}$ & 13.9 & -0.62 & $\underline{4.59}$ & 13.3 & $\underline{-0.61}$ \\
\hline & qPL6.1 & 6 & 6619487-6816224 & C & $\underline{4.91}$ & 10.3 & -0.55 & $\underline{5.92}$ & 18.4 & -0.72 & $\underline{5.01}$ & 14.4 & $\underline{0.66}$ & $\underline{4.81}$ & 13.9 & $\underline{0.64}$ \\
\hline & qPL7.1 & 7 & id7003853-id7004922 & । & & & & 2.84 & 8.4 & 0.49 & 3.29 & 9.7 & -0.56 & $\underline{3.62}$ & 10.7 & -0.58 \\
\hline & aPL9.1 & 9 & 9592671-9869869 & 1 & & & & 3.36 & 20.4 & 0.73 & 3.27 & 9.7 & -0.83 & 2.92 & 8.7 & -0.73 \\
\hline
\end{tabular}


Table 4 QTLs for yield in agronomic traits from a RIL population of Ciherang-Sub1/R10F365 identified under irrigated control condition (Continued)

\begin{tabular}{|c|c|c|c|c|c|c|c|c|c|c|c|c|c|c|c|c|}
\hline \multirow[t]{2}{*}{ PN } & qPN1.1 & 1 & $147907-395936$ & 1 & & & & 2.55 & 7.6 & 0.39 & 3.49 & 10.3 & -0.55 & 3.16 & 9.4 & -0.55 \\
\hline & qPN3.1 & 3 & $2573346-2610698$ & I & & & & 2.88 & 8.9 & 0.43 & 2.74 & 8.2 & -0.47 & 2.83 & 8.4 & -0.44 \\
\hline \multirow[t]{2}{*}{ BM } & $q B M 1.1$ & 1 & $147907-275443$ & 1 & 3.92 & 10.2 & 51.73 & 2.44 & 72.0 & 43.16 & 3.68 & 10.8 & -50.83 & 2.30 & 6.9 & -42.4 \\
\hline & $q B M 3.1$ & 3 & 2499734-2560888 & C & 2.89 & 7.0 & -45.20 & & & & 3.33 & 9.9 & 49.64 & & & \\
\hline
\end{tabular}

${ }^{a} G W 100$ grain weight, DTF days to flowering, $F L W$ flag leaf width, $F L L$ flag leaf length, $G Y$ grain yield per plot, $H I$ harvest index, $L S L_{1}, L S L_{2}$, and $L S L_{3}$, respectively leaf sheath length for the first, second and third internodes, SER shoot elongation rate, $P H$ plant height, $T N$ number of tillers, $P L$ panicle length, $P N$ number of panicles, and $B M$ shoot biomass

${ }^{b)} \mathrm{C}$ : Ciherang-Sub1; I: IR10F365

c) underlined and bold numbers: significant at $P \leq 0.01$; bold numbers: significant at $P \leq 0.05$; italic: not significant but with LOD $\geq 2.0$

traits. Most of the QTLs were in similar positions as previously reported QTLs (Tables 5 and 6).

\section{QTLs for GY, GW, HI, and SR}

Three QTLs were detected for grain yield under stagnant flooding, qGY3.1, qGY5.1 and qGY6.1. (Table 3,
Fig. 1). It is noteworthy that the largest QTL, $q G Y 3.1$ with an LOD score of 6.2 and phenotypic variation $\left(\mathrm{R}^{2}\right)$ of $14.3 \%$ was detected on the top of chromosome $3 \mathrm{~S}$ as a cluster with four other QTLs: qDTF3.1, which was detected in both environments, $q$ GW3.1, qFLW3.1, and $q P H 3.1$. Interestingly, the alleles that increase the effects

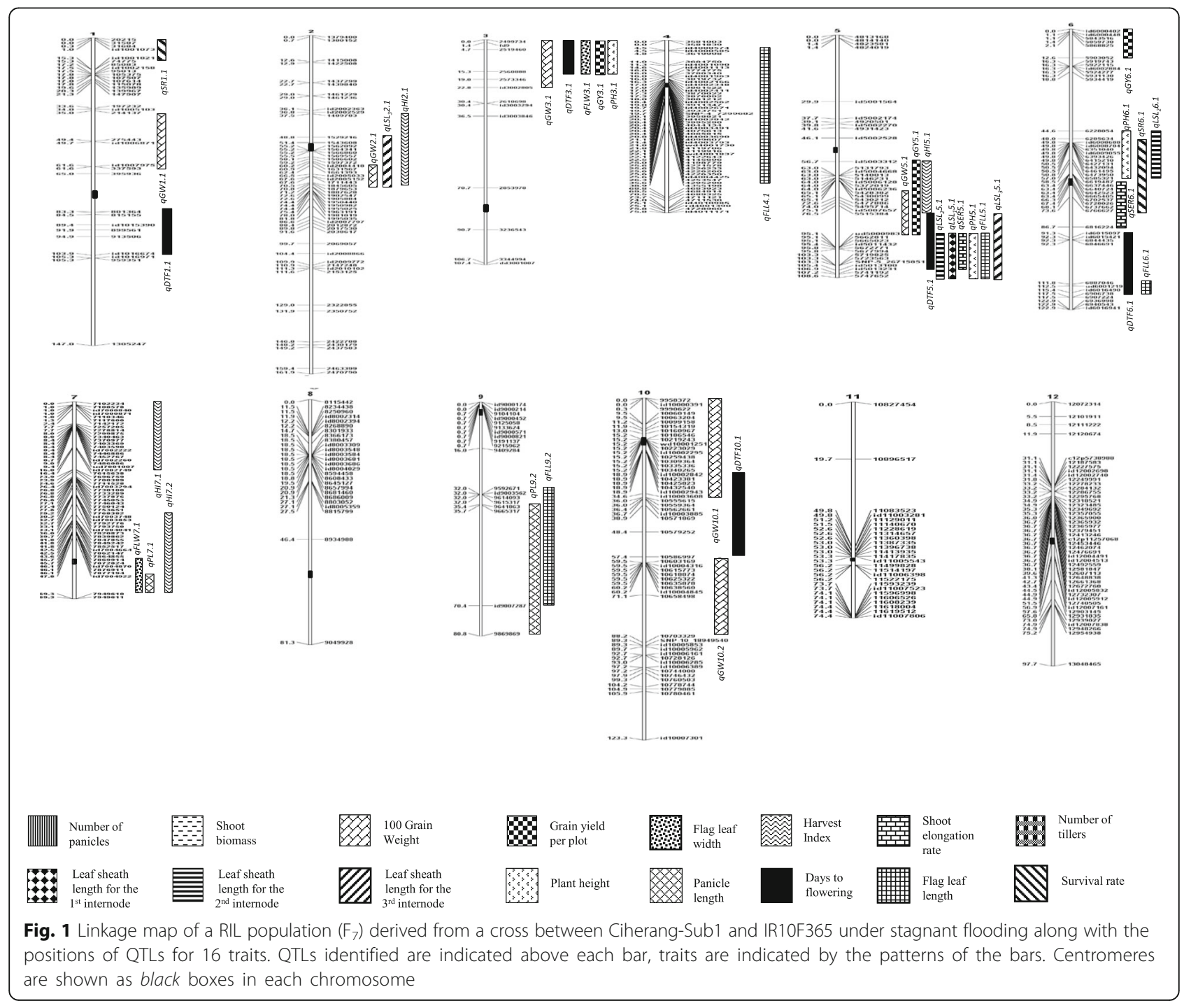




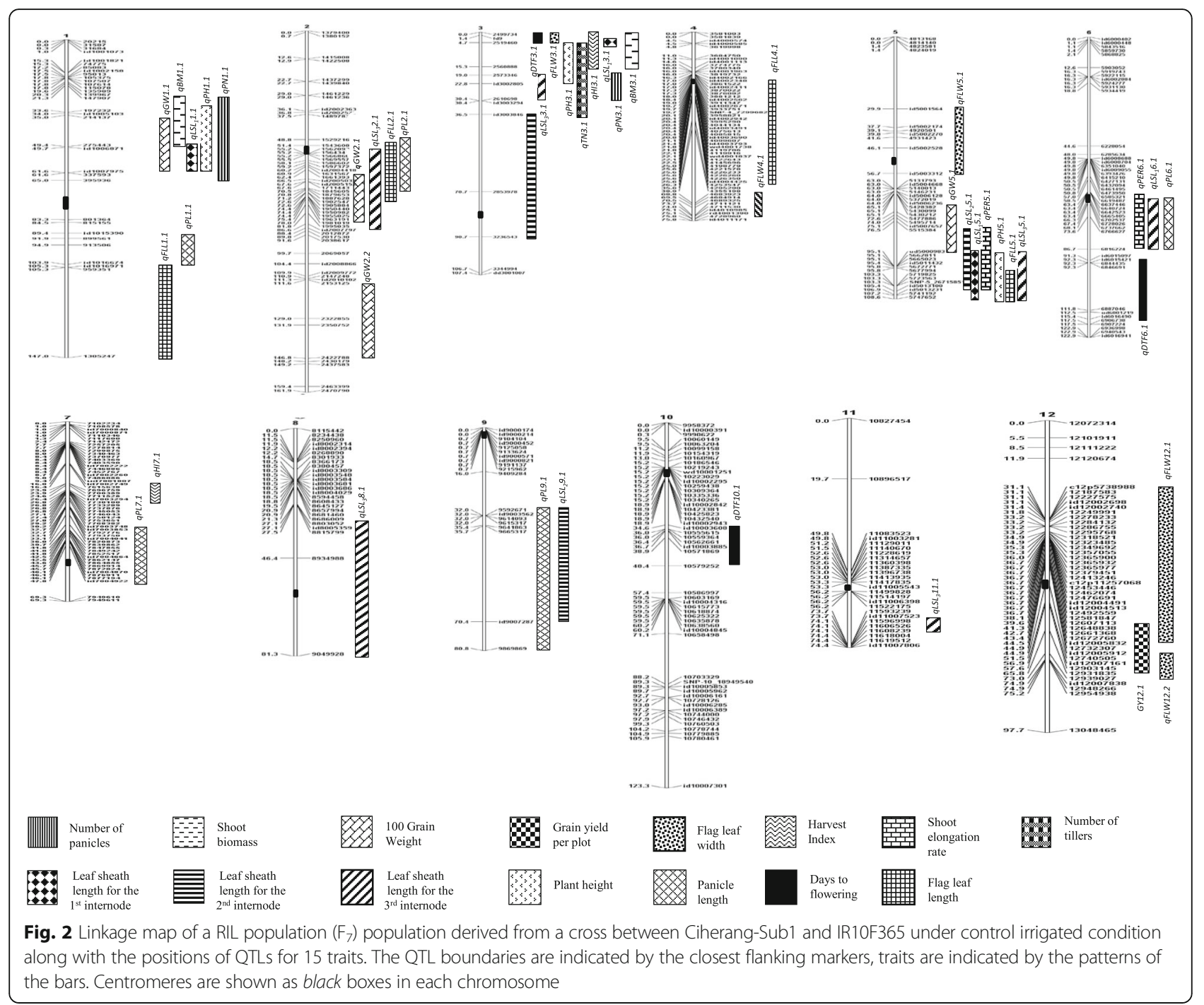

of all the QTLs in this cluster came from CiherangSub1. qGY3.1 was also detected in similar regions as previous reported by Xiao et al. (1996)) under irrigated condition, (Moncada et al. 2001) under upland cultivation, and (Bernier et al. 2007) under drought condition (Table 5). Another QTL, qGY5.1 (LOD = 3.66, $\mathrm{R}^{2}=12.2 \%$ ) was in a cluster with two other QTLs of different traits on the upper part of chromosome $5 \mathrm{~L}, q G W 5.1$, which was detected in both environments, and qHI5.1. However, the increased-alleles of $q$ GY5.1 and qHI5.1 were from IR10F365, while that of $q G W 5.1$ was from CiherangSub1 (Table 3, Fig. 1). qGY5.1 was also detected in the similar region as $q Y l-5$ (Cho et al. 2003). Under control conditions, only one QTL for grain yield, $q$ GY12.1 was detected (LOD $=3.39$ and $\mathrm{R}^{2}=9.3$ ) (Table 4, Fig. 2); this QTL partially overlapped with qFLW12.1 and in the same region as a major QTL for yield under drought (Bernier et al. 2007) (Table 6). It is interesting to note that some of the GY QTLs detected in this study were in similar positions as previously identified GY QTLs, under different environments. However, further research is needed to determine whether they are governed by the same gene(s) or they are simply closely linked.

Six QTLs were detected for 100-grain weight under SF on chromosomes 1, 2, 3, 5, and 10 (2 QTLs). All alleles with increasing effects were from Ciherang-Sub1 except for the largest QTL, $q$ GW10.2 (LOD $=6.30$ and $\mathrm{R}^{2}=13.1 \%$ ) on chromosome 10S (Table 3, Fig. 1). $q G W 1.1$ was also detected as the largest QTL for GW under control conditions in this study (LOD $=5.34$ and $\mathrm{R}^{2}=15.2 \%$ ) and co-localized with GW1-1 (Yu et al. 2008) (Table 5). $q G W 2.1$ was in the similar region as tgw2 (Yoon et al. 2006) and in a cluster with $q L S I 3-2.1$ and $q H I 2$; however, the increased-allele for $q H I 2$ was from IR10F365. qGW3.1 was co-localized with $Q K w 3 a$ (Li et al. 1997) and in a cluster with other four QTLs detected on chromosome 3S. qGW5.1 was in the 
Table 5 Genomic positions of QTLs identified in stagnant flooding with its QTL cluster and comparison to the QTLs identified in control irrigated condition in this study and previously published QTLS

\begin{tabular}{|c|c|}
\hline QTL & Studies shared common region \\
\hline qGY3.1 & $\begin{array}{l}\text { (Xiao et al. 1996); dth3.1: (Moncada et al. 2001); qt/3.1: (Bernier et al. 2007); qPH3.1, qFLW3.1, qGW3.1: this study under SF; qDTF3.1: this study } \\
\text { under SF and control }\end{array}$ \\
\hline qGY5.1 & qYI-5: (Cho et al. 2003); qGW5.1: this study under SF and control; qHI5.1: this study under SF \\
\hline qGY6.1 & qDTY6.1: (Venuprasad et al. 2012) \\
\hline qGW1.1 & GW1-2: (Yu et al. 2008); qGW1.1: this study under control \\
\hline qGW2.1 & tgw2: (Yoon et al. 2006); $9 H I 2.1, a L S L_{3} 2.1:$ this study under SF \\
\hline qGW3.1 & QKw3a: (Li et al. 1997); qPH3.1, aFLW3.1, qGY3.1: this study under SF; qDTF3.1: this study under SF and control \\
\hline qGW5.1 & gw-5: (Lu et al. 1997); qGW5.1: this study under control qHI5.1 and qGY5.1: this study under SF \\
\hline qGW10.1 & QKw10: (Li et al. 1997) \\
\hline qGW10.2 & (Ishimaru 2003); gw10.1: (Thomson et al. 2003) \\
\hline qHI2.1 & $q G W 2.1$ and $q L S L_{3} 2.1$ : this study under SF \\
\hline qHI5.1 & qGW5.1: this study SF and control; qGY5.1: this study under SF \\
\hline qHI7.1 & none \\
\hline qHI7.2 & QPL7.1 and GFLW7.1: this study under SF \\
\hline qSR1.1 & none \\
\hline qSR6.1 & qSER6.1: this study under SF and control \\
\hline qPL7.1 & (Mei et al. 2003); qHI7.2, qFLW7.1: this study under SF \\
\hline qPL9.1 & $\begin{array}{l}\text { qPL-9: (Cho et al. 2003); p19.1: (Septiningsih et al. 2003); p19.1: (Thomson et al. 2003); (Marri et al. 2005); (Li et al. 2006); qPL9.1: this study } \\
\text { under control }\end{array}$ \\
\hline qPH3.1 & (Li et al. 1997); qPh3a: (Li et al. 2003); qGY3.1, qFLW3.1, qGW3.1: this study under SF; qDTF3.1: this study under SF and control \\
\hline qPH5.1 & $\begin{array}{l}\text { (Mei et al. 2003); ph5.1: (Moncada et al. 2001); ph5.1: (Thomson et al. 2003); qPH5.1: this study under control; qLSL, 5.1, qLSI2-5.1, qLSI3-5.1, } \\
\text { qSER5.1, aFLL5.1 and qDTF5.1: this study under SF and control }\end{array}$ \\
\hline qPH6.1 & ph6: (Xiao et al. 1996); qPH2-6-1: (Cui et al. 2004); qLSL26.1: this study under SF \\
\hline 9SER5.1 & QSER5.1: this study under control; qPH5.1, qLSL 5.1, aLSI25.1, qLSI/35.1, QSER5.1, qFLL5.1, and DTF5.1: this study under SF and control \\
\hline qSER6.1 & qSR6.1: this study under SF and control \\
\hline$q L S L, 5.1$ & qLSL 15.1: this study under control; qPH5.1, qLSL 5.1 ; qLSL 5.1, qSER5.1, qFLL5.1, and DTF5.1: this study under SF and control \\
\hline$q L S L_{2} 5.1$ & qLSL 5.1 : this study undercontrol; $9 P H 5.1,9 L S L_{1} 5.1$ and $9 L S L_{3} 5.1$, aSER5.1, qFLL5: this study under SF and control; DTF5.1: this study under SF \\
\hline$q L S L_{2} 6.1$ & qPH6.1: this study under SF \\
\hline$q L S L_{3} 2.1$ & qHI2.1 and qGW2.1: this study under SF \\
\hline$q L S L_{3} 5.1$ & qLSL 3 5.1: this study under control; qPH5.1, qLSL 5.1 , qLSL25.1, qSER5.1, and qFLL5.1: this study under SF and control; DTF5.1: under SF \\
\hline qFLL4.1 & (Mei et al. 2005) \\
\hline qFLL5.1 & $\begin{array}{l}\text { QFII7: (Bing et al. 2006); (Yan et al. 2003); qFLL5.1: this study under irrigated; qPH5.1, aLSI1-5.1, aLSL25.1, qLSL } 35.1 \text {, qSER5.1: this study under SF } \\
\text { and control; DTF5.1: this study under SF }\end{array}$ \\
\hline qFLL6.1 & (Mei et al. 2005); qDTF6.1: this study under SF and control \\
\hline qFLL9.1 & fll9: (Yan et al. 1999); qPL9.1: this study under SF and control \\
\hline qFLW3.1 & qPH3.1, qGW3.1, qGY3.1: this study under SF; qDTF3.1: this study SF and control \\
\hline qFLW7.1 & qHI7.2, qPL7.1: this study under SF \\
\hline qDTF1.1 & qDTH-1: (Cho et al. 2003); QHd1b: (Li et al. 2003); (Mei et al. 2003); qFLL6.1 : this study under SF \\
\hline qDTF3.1 & $\begin{array}{l}\text { (Albar et al. 1998); dth3.1: (Moncada et al. 2001); qHD-3-1: (Takeuchi et al. 2001); qHDD3-1: (Hittalmani et al. 2003); QHd3a: (Li et al. 2003); } \\
\text { (Mei et al. 2003); qEMF3: (Hirabayashi et al. 2014); qDTF3.1: this study under control; qGW3.1, qFLW3.1, qPH3.1, qGY3.1: this study under SF }\end{array}$ \\
\hline qDTF5.1 & (Li et al. 1998); QHd5b: (Li et al. 2003); qPH5.1, qLSL15.1, qLSL25.1, qLSL 35.1, qSER5.1, and qFLL5.1: this study under SF and control \\
\hline qDTF6.1 & QHd66: (Li et al. 2003); (Mei et al. 2003); qDTF6.1: this study under control; qFLL6.1: this study under SF \\
\hline qDTF10.1 & (Price et al. 1997); (Li et al. 1998); qDTF10.1:this study under control \\
\hline
\end{tabular}


Table 6 Genomic positions of QTLs identified in control irrigated condition with its QTL cluster and comparison to the QTLS identified in stagnant flooding in this study and previously published QTLS

\begin{tabular}{ll}
\hline QTL & Studies shared common region \\
\hline qGY12.1 & qt112.1: (Bernier et al. 2007) \\
qGW1.1 & GW1-2: (Yu et al. 2008); qGW1.1: this study under SF \\
qGW2.1 & gw-2: (Lu et al. 1997); QKW26: (Li et al. 1997); qGW-2: (Cho et al. 2003); KW2-2: (Gao et al. 2004); qLSL32.1: this study under control \\
qGW2.2 & QKW2a: (Li et al. 1997); qTGWT-2-2: (Zhuang et al. 2002); tgw2: (Ishimaru 2003); gw2.1: (Thomson et al. 2003); qTGW-2a: (Zou et al. 2005) \\
qGW5.1 & gw-5: (Lu et al. 1997); QKW5: (Li et al. 1997); qGW5.1: this study under SF \\
qHI3.1 & qhi3.3/qhi3.4/qhi3.5: (Lanceras et al. 2004); qFLW3.1, qDTH3.1: this study under control and SF; qLSL 3.1, qBM3.1: this study under control \\
qHI7.1 & none \\
qTN3.1 & TN(R3): (Kobayashi et al. 2003); qPN3.1, qLSL33.1: this study under control \\
qPN1.1 & PnN(R3-1): (Kobayashi et al. 2003); npp(1.1): Nagata et al. 2002; qBM1.1: this study under control \\
qPN3.1 & PN(3): (Jiang et al. 2004); qFLW3.1, qDTH3.1: this study under control and SF; qTN3.1, qLSL33.1: this study under control \\
qBM1.1 & PW(1): (Lian et al. 2005); qPN1.1: this study under control \\
qBM3.1 & qHI3.1; qLSL13.1: this study under control \\
qPL1.1 & (Mei et al. 2005) \\
qPL2.1 & pl2: (Xing et al. 2001); qPL2-1: (Cui et al. 2002); (Mei et al. 2003) 3; qFLL2.1: this study under control \\
qPL6.1 & (Mei et al. 2003); PL(6): (Jiang et al. 2004) J; qSER6.1, qLSL36.1: this study under control \\
qPL7.1 & (Mei et al. 2005) \\
qPL9.1 & pl9: (Xing et al. 2001); qPL-9: (Cho et al. 2003); pl9.1: (Septiningsih et al. 2003); pl9.1: (Thomson et al. 2003); (Marri et al. 2005); (Li et al. 2006);
\end{tabular}
QPL9.1: this study under SF

QPH1.1 (Li et al. 1998); (Mei et al. 2003); qLSL11.1: this study under control

qPH3.1 (Li et al. 1997); QPh3a: (Li et al. 2003)

qPH5.1 (Mei et al. 2003); ph5.1: (Moncada et al. 2001); (Thomson et al. 2003); qPH5.1: this study under SF; qLSL, 5.1, qLSL25.1, qLSL_5.1, qSER5.1, qFLL5.1: this study under control and SF

qSER5.1 GSER5.1: this study under SF; qPH5.1, qLSL__5.1, qLS12-5.1, aLSL 5.1, qFLL5.1: this study under control and SF

qSER6.1 GSER6.1: this study under SF; qPL6.1, qLSL 6.1: this study under control

qLSL $1.1 \quad$ QPH1.1: this study under control

qLSL $3.1 \quad$ qBM3.1, $q H 13.1$ : this study under control

qLSL, 5.1 GLSL 5.1: this study under SF; qPH5.1, qLSL $5.1,9 L S L_{3} 5.1$, qSER5.1, qFLL5.1: this study under control and SF

$q L S L_{2} 3.1$ none

qLSL25.1 qLSL 25.1 : this study under SF; qPH5.1, qLSL 5.1, qLSL 5 5.1, qSER5.1, qFLL5.1: this study under control and SF

$q L S L_{2} 9.1 \quad$ none

qLSL $2.1 \quad$ GGW2.1: this study under control

qLSL 3.1 aTN3.1, qPN3.1: this study under control

qLSL $L_{3} 5.1 \quad q L S L_{3} 5.1$ : this study under SF; qPH5.1, qSER5.1, qLSL 5.1, qLSL 25.1 , qFLL5.1: this study under control and SF

qLSL $L_{3} 6.1$ qSER6.1: this study under control and $S F ; q P L 6.1$ : this study under control

$q L S I_{3} 8.1 \quad$ none

$q L S L_{3} 11.1$ none

qFLL1.1 (Mei et al. 2005)

GFLL2.1 GPL2.1: this study under irrigated

qFLL4.1 (Mei et al. 2005)

qFLL5.1 QFII7: Yue et al. 2006; Yan et al. 2003; qFLL5.1: this study under SF; qPH5.1, qLSL, 5.1, qLSL25.1, qLSL 55.1, qSER5.1: this study under irrigated and SF

qFLW3.1 (Mei et al. 2005); qFLW3.1: this study under SF; qHI3.1, aBM3.1, and qLSL,3.1: this study under irrigated); qDTF3.1: this study under irrigated and SF

qFLW4.1 QFIw4: (Bing et al. 2006); flw4: (Yan et al. 1999)

qFLW5.1 none 
Table 6 Genomic positions of QTLs identified in control irrigated condition with its QTL cluster and comparison to the QTLs identified in stagnant flooding in this study and previously published QTLS (Continued)

GFLW12.1 none

qFLW12.2 (Mei et al. 2005)

qDTF3.1 (Albar et al. 1998); dth3.1: (Moncada et al. 2001); qHD-3-1: (Takeuchi et al. 2001); Hd9: (Lin et al. 2002) 2; qHDD3-1: (Hittalmani et al. 2003); QHd3a: (Li et al. 2003); (Mei et al. 2003); qEMF3: (Hirabayashi et al. 2014); qDTF3.1: this study under SF; qFLW3.1: this study under control and SF; qHI3.1, qBM3.1, and $q L S L_{1} 3.1$ : this study under control

qDTF6.1 QHd6b: (Li et al. 2003); (Mei et al. 2003); qDTF6.1: this study under SF

qDTF10.1 (Price et al. 1997); Li et al. (1998)); qDTF10.1: this study under SF

similar region as $g w-5$ (Lu et al., 1997); the same QTL was also detected in the same position in the control and in a cluster with other two QTLs on the upper part of chromosome 5 L. $q G W 10.1$ was co-localized with QKW10 (Li et al. 1997); while $q G W 10.2$ was in the similar regions of the QTLs detected by Ishimaru (2003) and Thomson et al. (2003). Under control conditions, four QTLs were detected on chromosomes 1, 2 (2 QTLs) and 5. In all cases the source of the increased alleles were from Ciherang-Sub1 (Table 4, Fig. 2). The two QTLs on chromosome 2 were co-localized with many previous reported QTLs; in addition, $q G W 2.1$ was in a similar region of $q \mathrm{LSI}_{3} 2.1$ (Table 6).

Four harvest index QTLs were detected under stagnant flooding located on chromosomes 2, 5 and 7 (2 QTLs). The largest QTL, qHI7.2 (LOD $=8.67$ and $\left.\mathrm{R}^{2}=20.4 \%\right)$ was the only one that had the increased allele from IR10F365 (Table 3, Fig. 1). This QTL was co-localized with two other QTLs, qPL7.1 and qFLW7.1; however, the increased-allele of $q F L W 7.1$ was from Ciherang-Sub1. Under control conditions, two QTLs were identified on chromosomes 3 and 7, with the largest one, qHI3.1, detected with a LOD of 4.91 and $\mathrm{R}^{2}$ of $14.2 \%$ (Table 4, Fig. 2). On the other hand, only two minor QTLs for survival rate under stagnant flooding were identified on chromosomes 1 and 6, qSR1.1 ( $\mathrm{LOD}=2.89$ and $\left.\mathrm{R}^{2}=10.0 \%\right)$ with the beneficial allele from IR10F365 and qSR6.1 $(\mathrm{LOD}=2.97$ and $R^{2}=7.3 \%$ ) with that of Ciherang-Sub1, respectively (Table 3, Fig. 1). qSR6.1 was in a cluster with three other QTLs, qSER6.1, which was detected in both environments, $q P H 6.1$, and $q L S L_{2} 6.1$; however, the increasedallele in $q P H 6.1$ was from IR10F365.

\section{QTLs for DTF, PH, SER and PL}

Five QTLs were detected for days to flowering under SF on chromosomes 1, 3, 5, 6, and 10 (Table 3, Fig. 1). Interestingly, the three QTLs on chromosomes 3, 6 and 10 were also mapped in similar regions under control conditions (Table 4, Fig. 2). The largest QTL was qDTF3.1 with an increased allele or lateness from Ciherang-Sub1 ( $\mathrm{LOD}=12.51$ and $\mathrm{R}^{2}=26.0 \%$ in stress; $\mathrm{LOD}=21.81$ and $\mathrm{R}^{2}=42.19 \%$ in the control); while the other two QTLs, qDTF6.1 and qDTF10.1, with lateness from IR10F365. qDTF5.1 was strongly detected by both software but only under SF, on the lower part of chromosomes $5 \mathrm{~L}\left(\mathrm{LOD}=4.11\right.$ and $\left.\mathrm{R}^{2}=7.0 \%\right)$ in a cluster with six other QTLs, $q L S L_{1} 5.1, q L S L_{2} 5.1, q L S L_{3} 5.1$, qSER5.1, qPH5.1, and qFLL5.1 (Table 5). All of the QTLs for DTF detected in this study were previously reported in similar positions by other researchers (Tables 5 and 6).

Three QTLs were detected for plant height on chromosomes 3, 5 and 6 under SF, with the largest, qPH5.1 $\left(\mathrm{LOD}=5.59\right.$ and $\left.\mathrm{R}^{2}=12.1 \%\right)$ on the lower arm of chromosome $5 \mathrm{~L}$ with an increased-allele from IR10F365 (Table 3, Fig. 1). Under control conditions, the same QTL was detected with larger effect (LOD $=9.90$ and $\mathrm{R}^{2}=23.9 \%$ ) (Table 4, Fig. 2). The QTL on chromosome 3, qPH3.1, was also detected under control condition with partly overlapping position; with an increased effect from Ciherang-Sub1. A minor QTL, $q P H 1.1$ was also detected on chromosome 1 under control conditions, with an increased allele effect from CiherangSub1. All of the PH QTLs detected in this study were previously reported in similar positions by other researchers (Tables 5 and 6). On a related trait, two QTLs were detected for shoot elongation rate under SF on chromosomes 5 and 6. The largest QTL, qSER5.1 ( $\mathrm{LOD}=12.46$ and $\mathrm{R}^{2}=32 \%$ ) positioned in a cluster of QTLs on the lower part of chromosome 5L (Table 3, Fig. 1), with an increased allele from IR10F365. The second QTL, qSER6.1 was a minor one with the increased-allele effect from Ciherang-Sub1. It was worth noting that under control, both QTLs were mapped at the same positions on chromosomes 5 and 6 (Table 4, Fig. 2).

Under SF, two QTLs for panicle length qPL7.1 and qPL9.1 were identified with increase alleles from IR10F365 (Table 3, Fig. 1). qPL7.1 was the largest with an LOD value of 5.47 and $R^{2}$ of $22 \%$. Under control condition, five QTLs were detected on chromosomes 1, 2, 6, 7 and 9 (Table 4, Fig. 2). Three of them had increased alleles from IR10F365, including the largest QTL $q$ PL2.1 ( $\mathrm{LOD}=7.11$ and $\left.\mathrm{R}^{2}=14.31 \%\right)$. $q P L 9.1$ was detected under both SF and control, sharing the same region on the lower arm of chromosome $9 \mathrm{~L}$. The panicle length QTLs detected in this study have 
also been previously mapped in similar positions (Tables 5 and 6).

\section{QTLs for FLL and FLW}

Four QTLs were identified for flag leaf length under SF on chromosomes 4, 5, 6, and 9 (Table 3, Fig. 1). Three of the QTLs had increased alleles from IR10F365, including the largest QTL $q F L L 5.1\left(\mathrm{LOD}=6.18 ; \mathrm{R}^{2}=14.0 \%\right)$ positioned in a cluster with other QTLs on the lower part of chromosome 5L; the same QTL was also detected under control conditions. Under the control, four QTLs were identified on chromosomes $1,2,4$, and 5 , with three of them had increased alleles from IR10F365 (Table 4, Fig. 2). For flag leaf width, two QTLs, qFLW3.1 (LOD = 4.00 and $\left.\mathrm{R}^{2}=11.3 \%\right)$ and $q F L W 7.1\left(\mathrm{LOD}=3.11\right.$ and $\mathrm{R}^{2}$ $=14.0 \%$ ) were detected under SF with their increased allele from Ciherang-Sub1 (Table 3, Fig. 1). Under the control, 5 QTLs were detected on chromosomes 3, 4, 5 and 12 (2 QTLs), $q F L W 12.1$ being the only QTL having increased allele from IR10F365 (Table 4, Fig. 2). qFLW4.1 was the largest under the control, with an LOD score of 8.88 and $\mathrm{R}^{2}$ of $20.11 \%$. The positions of qFLW3.1 mostly overlap under SF and control conditions. Most of the FLL and FLW QTLs were previously mapped in similar regions (Tables 5 and 6).

\section{QTLs for $L S L$}

Under SF, only one QTL for leaf sheath length for the first internode, $q L S L_{1} 5.1$ with increased allele from IR10F365, was detected ( $\mathrm{LOD}=4.44$ and $\left.\mathrm{R}^{2}=11.0 \%\right)$ in a cluster of QTLs, including $q L S L_{2} 5.1$ and $q L S L_{3} 5.1$, on the lower arm of chromosome $5 \mathrm{~L}$ (Table 3, Fig. 1). Three QTLs were identified under control on chromosomes 1,3 , and 5 (Table 4, Fig. 2). $q L S L_{1} 5.1$ was detected in the same position as in SF condition as the largest QTL in irrigated ( $L O D=5.33$ and $R^{2}=13.1 \%$ ). The other two QTLs had increased alleles from Ciherang-Sub1. Meanwhile for $\mathrm{LSL}_{2}$, two QTLs were identified on chromosomes 5 and 6 under SF, with the increased alleles from IR10F365 (Table 3, Fig. 1). $q L S L_{2} 5.1$ was the largest QTL $\left(\mathrm{LOD}=4.96\right.$ and $\left.\mathrm{R}^{2}=14.3 \%\right)$. Under control, three QTLs were detected on chromosomes 3, 5, and 9 (Table 4, Fig. 2). Two of the QTLs had increased alleles effects from IR10F365, including $q L S L_{2} 5.1$, which was also identified at the same position as under SF. This QTL was also the largest QTL under control $(\mathrm{LOD}=4.95$ and $\mathrm{R}^{2}=11.2 \%$ ). Two QTLs for $\mathrm{LSL}_{3}$ were detected under SF, located on chromosomes 2 and 5 with the increased allele from Ciherang-Sub1 and IR10F365, respectively (Table 3, Fig. 1). The largest QTL was $q L S L_{3} 2.1$ on chromosome $2\left(\mathrm{LOD}=4.16\right.$ and $\left.\mathrm{R}^{2}=10.0 \%\right) . q L S L_{3} 5.1$ was mapped on a cluster of QTLs on the lower part of chromosome 5L. Meanwhile, under control, six QTLs were identified and four of the QTLs had increased alleles from Ciherang-Sub1 (Table 4, Fig. 2). The LOD values of the QTLs ranged from 4.40 - 7.41 and $\mathrm{R}^{2}$ of $9.26-14.72 \%$. The largest QTL was $q L S L_{3} 8.1$, with the increased allele from IR10F365. $q L S L_{3} 2.1$ and $q L S L_{3} 5.1$ were also mapped in similar positions on chromosomes 2 and 5, respectively, as in SF environment. Some of these LSL traits were mapped in a cluster with other traits (Tables 5 and 6).

\section{QTLs for $T N, P N$, and $B M$}

There were no QTLs detected for tiller number, panicle number and shoot biomass under stagnant flooding. While under control conditions, only one QTL detected for tiller number on top of chromosome 3S, qTN3.1 $\left(\mathrm{LOD}=4.29, \mathrm{R}^{2}=12.5 \%\right)$, with increased allele from IR10F365, in a cluster with some other QTLs, qPH3.1, qHI3.1, qPN3.1, $q B M 3.1$, and $q L S L_{3} 3.1$ (Table 4, Fig. 2). Two QTLs were identified for panicle number under control on chromosomes 1 and 3 with the increased alleles from IR10F365. $q$ PN1.1 $\left(\mathrm{LOD}=3.49\right.$ and $\mathrm{R}^{2}=10.3 \%$ ) was detected in a cluster with some other QTLs qPH1.1, $q G W 1.1, q B M 1.1$, and $q L S L_{1} 1.1$, on the lower part of chromosome 1S. Two QTLs were detected under control for shoot biomass, $q B M 1.1$ ( $\mathrm{LOD}=3.92$ and $\mathrm{R}^{2}=10.2 \%$ ) and $q B M 3.1$ ( $\mathrm{LOD}=3.33$ and $\mathrm{R}^{2}=9.9 \%$ ), with the increased-alleles from IR10F365 and Ciherang-Sub1, respectively. Similar QTLs for the three traits had been previously detected in the similar regions (Tables 5 and 6).

Our results demonstrated that combinations of three or two yield QTLs gave better performances under stagnant flooding conditions (Table 7). Under control conditions, however, $q G Y 12$ only had a small contribution for increasing yield (7.2\%; Table 8). A group of RILs having combinations of three QTLs gave the best performance under stagnant flooding with an increased yield of $89.2,56.1,44.3,51.5,30.6,17.2$, and $37.6 \%$ compared to the RIL that did not possess any of the yield QTLs, only qGY6 from Ciherang-Sub1, only $q G Y 5$ from IR10F365, only $q G Y 3$ from Ciherang-Sub1 (detected in a cluster with four different QTLs referred as C3S QTLs in Table 7), $q G Y 5$ and $q G Y 6, q G Y 3$ and $q G Y 6$, and $q G Y 3$ and $q G Y 5$, respectively. In general the groups having higher yield under SF also are taller, have more tillers and panicles, longer flag leaf, more biomass, higher shoot elongation rate, longer leaf sheaths, and higher survival rate. A similar cluster of QTLs on the top of chromosome 3 (C3S QTLs; Table 8), however, hardy had any effect in yield under control; either alleles contributed similarly to yield. This might be due to the fact that the beneficial alleles of those QTLs detected in the control were mix from both parents (Tables 7 and 8; Fig. 2). On the other hand, a cluster of seven different QTLs on the lower part of chromosome 5L just below $q$ GY5 (C5L QTLs; Table 7) revealed that these QTLs indirectly contribute to a yield increase of $19.5 \%$ 


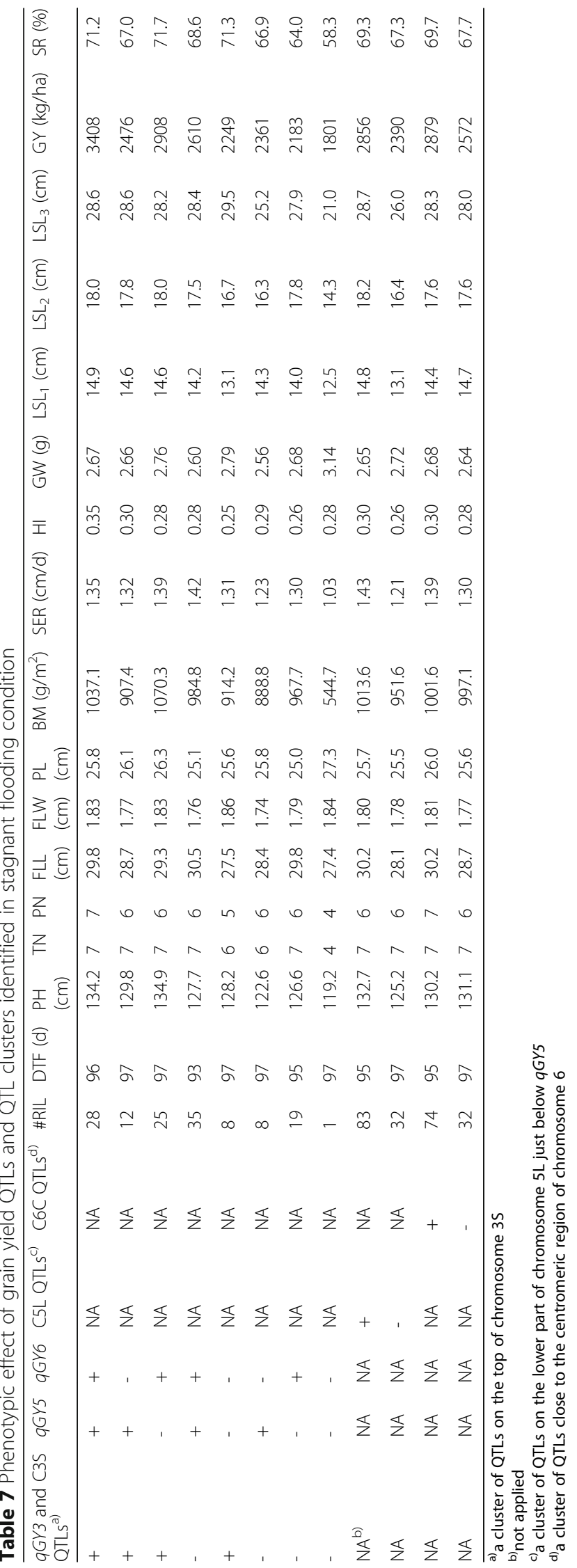


Table 8 Phenotypic effect of grain yield QTL and QTL clusters identified in irrigated control conditions

\begin{tabular}{|c|c|c|c|c|c|c|c|c|c|c|c|c|c|c|c|c|c|c|c|}
\hline qGY12 & (3S QTLs ${ }^{b)}$ & (5L QTLs) & (6C QTLs ${ }^{d)}$ & \#RIL & DTF & $\mathrm{PH}$ & TN & PN & FLL & FLW & $P L$ & $\mathrm{BM}$ & PER & $\mathrm{HI}$ & GW & $\mathrm{LSL}_{1}$ & $\mathrm{LSL}_{2}$ & $\mathrm{LSL}_{3}$ & GY \\
\hline+ & NA & NA & NA & 32 & 90 & 124.0 & 11 & 11 & 31.5 & 1.88 & 25.8 & 1372.2 & 1.33 & 0.44 & 2.71 & 13.9 & 21.6 & 31.5 & 5910 \\
\hline - & NA & NA & NA & 80 & 89 & 126.3 & 10 & 10 & 32.2 & 1.93 & 26.2 & 1323.3 & 1.35 & 0.43 & 2.74 & 14.1 & 22.6 & 33.2 & 5511 \\
\hline$N A^{a)}$ & + & NA & NA & 77 & 91 & 126.7 & 10 & 10 & 32.5 & 1.89 & 25.9 & 1358.8 & 1.31 & 0.42 & 2.73 & 14.9 & 21.9 & 33.2 & 5588 \\
\hline NA & - & NA & NA & 67 & 87 & 124.2 & 10 & 10 & 31.4 & 1.97 & 26.4 & 1290.1 & 1.37 & 0.45 & 2.73 & 13.4 & 22.6 & 32.2 & 5671 \\
\hline NA & NA & + & NA & 83 & 88 & 128.3 & 10 & 10 & 32.6 & 1.96 & 26.4 & 1321.8 & 1.40 & 0.44 & 2.72 & 14.9 & 22.6 & 33.4 & 5729 \\
\hline NA & NA & - & NA & 32 & 90 & 120.4 & 10 & 10 & 30.8 & 1.85 & 25.5 & 1359.0 & 1.22 & 0.42 & 2.77 & 13.2 & 20.8 & 31.3 & 5399 \\
\hline NA & NA & NA & + & 74 & 88 & 125.9 & 10 & 10 & 32.8 & 1.95 & 26.6 & 1337.2 & 1.37 & 0.44 & 2.75 & 14.2 & 22.3 & 32.8 & 5749 \\
\hline NA & NA & NA & - & 32 & 91 & 126.2 & 10 & 10 & 31.1 & 1.85 & 25.5 & 1350.7 & 1.26 & 0.42 & 2.70 & 14.7 & 22.1 & 32.0 & 5470 \\
\hline
\end{tabular}

a) not applied

b) a cluster of QTLs on the top of chromosome 35

c) a cluster of QTLs on the lower part of chromosome $5 \mathrm{~L}$ just below $q G Y 5$

d) a cluster of QTLs close to the centromeric region of chromosome 6

under stagnant flooding; which is partly due to increases in plant height, elongation rate, leaf sheath length, flag leaf length, and earliness from IR10F365 alleles. A similar cluster of six QTLs was also detected in the same region under control; in which this genomic region of IR10F365 indirectly increased yield by $6.1 \%$ (C5L QTLs; Table 8 ). Additionally, a smaller cluster of QTLs close to the centromeric region of chromosome 6 with increased alleles from Ciherang-Sub1 (C6C QTLs; Tables 7 and 8) contributed to a yield increase of 11.9 and $5.1 \%$ under SF and control, respectively.

\section{Conclusions}

This study reports the first effort for mapping beneficial QTLs under stagnant flooding conditions. In contrast to most Sub1-lines developed to date, Ciherang-Sub1 was found to be tolerant to stagnant flooding and many beneficial QTLs were derived from this variety. Future research in stagnant flooding tolerance should target these valuable QTLs after validation of trait data by conducting additional field trials across years and locations, especially on the distal part of chromosome 3 ( $q G Y 3$ and 4 other QTLs), $q G Y 5, q G Y 6$, clusters of QTLs on the lower part of chromosome $5 \mathrm{~L}$ and around the centromeric region of chromosome 6. These QTLs can be further investigated for molecular studies and for use in molecular breeding. In addition, since the two parents are elite breeding material, the best yielding lines that performed well in each environment can be further evaluated through multienvironmental trials. It should be noted that all of these RILs are already fixed for the SUB1 gene, which provides additional protection from complete submergence in both stagnant flooding and irrigated environments.

\section{Additional files}

Additional file 1: Table S1. List of traits measured in both stagnan flooding and irrigated control conditions. (DOCX $13 \mathrm{~kb}$ )
Additional file 2: Table S2. Performances of selected RILs in stagnant flooding and irrigated control IRRI fields in 2014 WS. (DOCX $13 \mathrm{~kb}$ )

Additional file 3: Figure S1. Percentage difference between means of trait values of 25 highest and lowest yielding lines relative to the mean of the population under stagnant flooding condition. (PDF $87 \mathrm{~kb}$ )

Additional file 4: Figure S2. Percentage difference between means of trait values of 25 highest and lowest yielding lines relative to the mean of the population under irrigated control condition. (PDF $85 \mathrm{~kb}$ )

Additional file 5: Figure S3. Relationship between shoot elongation rate (SER) under stagnant flooding condition, relative grain yield (ratio of yield under SF to that in the control) and survival rate (SR). (PPTX $46 \mathrm{~kb}$ )

Additional file 6: Table S3. Correlations among traits under stagnant flooding condition. (DOCX $15 \mathrm{~kb}$ )

Additional file 7: Table S4. Correlations among traits under irrigated control condition. (DOCX $15 \mathrm{~kb}$ )

\section{Acknowledgements}

We thank J. Borgonia and R. Formaran for field work assistance and the IRRI GSL team for genotyping assistance. The work reported here was supported in part by a grant from the Bill and Melinda Gates Foundation (BMGF) through the project "Stress-tolerant rice for Africa and South Asia (STRASA)" and also by the Global Rice Science Partnership (GRiSP), the National Institute of Food and Agriculture, U. S. Department of Agriculture, Hatch project 1009300.

\section{Authors' contributions}

EMS, AS, AMI designed the experiments; BCYC developed the RIL population using rapid generation advance (RGA); JC performed seed multiplication of the mapping population, ZJCG and AS performed DNA extraction, and AS and JC performed phenotyping under supervision of EMS; AS, EMS, and ZJCG analyzed the data; EMS and AS wrote the manuscript; all authors read and approved the manuscript.

\section{Competing interests}

The authors declare that they have no competing interests.

\section{Publisher's Note}

Springer Nature remains neutral with regard to jurisdictional claims in published maps and institutional affiliations.

\section{Author details}

'Present address: Rani Lakshmi Bai Central Agricultural University, Jhansi 284003, India. ${ }^{2}$ Present address: Sugar Research Australia, 71378 Bruce Highway, Meringa, PO Box122, Gordonvale, QLD 4865, Australia. ${ }^{3}$ Present address: Department of Soil and Crop Sciences, Texas A\&M University, College Station, TX 77843, USA. ${ }^{4}$ International Rice Research Institute, DAPO 7777, Metro Manila, Philippines. 


\section{Received: 27 February 2017 Accepted: 11 April 2017}

\section{Published online: 20 April 2017}

\section{References}

Albar L, Lorieux M, Ahmadi N, Rimbault I, Pinel A, Sy A, Ghesquière A (1998) Genetic basis and mapping of the resistance to rice yellow mottle virus. I. QTLs identification and relationship between resistance and plant morphology. Theor Appl Genet 97(7):1145-1154

Angaji SA, Septiningsih EM, Mackill DJ, Ismail AM (2010) QTLs associated with tolerance of flooding during germination in rice (Oryza sativa L.). Euphytica 172(2):159-168. doi:10.1007/s10681-009-0014-5

Baltazar MD, Ignacio JCl, Thomson MJ, Ismail AM, Mendioro MS, Septiningsih EM (2014) QTL mapping for tolerance of anaerobic germination from IR64 and the aus landrace Nanhi using SNP genotyping. Euphytica 197(2):251-260

Bernier J, Kumar A, Ramaiah V, Spaner D, Atlin G (2007) A large-effect QTL for grain yield under reproductive-stage drought stress in upland rice. Crop Sci 47(2):507-516

Bing Y, Wei-Ya X, Li-Jun L, Yong-Zhong X (2006) QTL analysis for flag leaf characteristics and their relationships with yield and yield traits in rice. Acta Genet $\operatorname{Sin} 33(9): 824-832$

Catling D (1992). Gas Exchange and Nutrition Rice in Deep Water. Springer, London, p 153-157

Cho Y, Suh J, Choi I, Hong H, Baek M, Kang K, Hwang H (2003). QTLs analysis of yield and its related traits in wild rice relative Oryza rufipogon. Treat Crop Res 4(1): 19-29.

Collard B, Septiningsih E, Das S, Carandang J, Sanchez D, Kato Y, AULA K (2013). Developing new flood-tolerant varieties at the International Rice Research Institute (IRRI). SABRAO J Breed Genet 45(1):42-56

Cui K, Peng S, Xing Y, Yu S, Xu C (2002) Genetic analysis of the panicle traits related to yield sink size of rice. Yi Chuan Xue Bao 29(2):144-152

Cui K, Peng S, Ying Y, Yu S, Xu C (2004) Molecular dissection of the relationships among tiller number, plant height and heading date in rice. Plant Prod Sci 7(3):309-318

Gao Y-M, Zhu J, Song Y-S, He C-X, Shi C-H, Xing Y-Z (2004) Analysis of digenic epistatic effects andQE interaction effects QTL controlling grain weight in rice. J Zhejiang Univ (Sci) 5(4):371-377

Gonzaga ZJC, Carandang J, Singh A, Collard BCY, Thomson MJ, \& Septiningshih EM (2017). Mapping QTLs for submergence tolerance in rice using a population fixed for SUB1A tolerant allele. Molecular Breeding. doi:10.1007/ s11032-017-0637-5

Hattori Y, Miura K, Asano K, Yamamoto E, Mori H, Kitano H, Ashikari M (2007) A major QTL confers rapid internode elongation in response to water rise in deepwater rice. Breed Sci 57(4):305-314

Hattori Y, Nagai K, Mori H, Kitano H, Matsuoka M, Ashikari M (2008) Mapping of three QTLs that regulate internode elongation in deepwater rice. Breed Sci 58(1):39-46

Hattori Y, Nagai K, Furukawa S, Song X-J, Kawano R, Sakakibara H, Kitano H (2009) The ethylene response factors SNORKEL1 and SNORKEL2 allow rice to adapt to deep water. Nature 460(7258):1026-1030

Hirabayashi H, Sasaki K, Kambe T, Gannaban RB, Miras MA, Mendioro MS, Takemoto-Kuno Y (2014). qEMF3, a novel QTL for the early-morning flowering trait from wild rice, Oryza officinalis, to mitigate heat stress damage at flowering in rice, O. sativa. J Exp Bot 66(5):1227-1236

Hittalmani S, Huang N, Courtois B, Venuprasad R, Shashidhar H, Zhuang J, Sidhu J (2003) Identification of QTL for growth-and grain yield-related traits in rice across nine locations of Asia. Theor Appl Genet 107(4):679-690

Iftekharuddaula K, Newaz M, Salam M, Ahmed H, Mahbub M, Septiningsih E, Mackill D (2011) Rapid and high-precision marker assisted backcrossing to introgress the SUB1 QTL into BR11, the rainfed lowland rice mega variety of Bangladesh. Euphytica 178(1):83-97

Iftekharuddaula KM, Ahmed HU, Ghosal S, Amin A, Moni ZR, Ray BP, Septiningsih EM (2016) Development of early maturing submergence-tolerant rice varieties for Bangladesh. Field Crop Res 190:44-53. doi:10.1016/j.fcr.2015.12.001

Ishimaru K (2003) Identification of a locus increasing rice yield and physiological analysis of its function. Plant Physiol 133(3):1083-1090

Ismail AM, Ella ES, Vergara GV, Mackill DJ (2009) Mechanisms associated with tolerance to flooding during germination and early seedling growth in rice (Oryza sativa). Ann Bot 103(2):197-209. doi:10.1093/aob/men211

Ismail AM, Singh US, Singh S, Dar MH, Mackill DJ (2013) The contribution of submergence-tolerant (Sub1) rice varieties to food security in flood-prone rainfed lowland areas in Asia. Field Crop Res 152:83-93
Jiang G, Xu C, Li X, He Y (2004) Characterization of the genetic basis for yield and its component traits of rice revealed by doubled haploid population. Yi Chuan Xue Bao 31(1):63-72

Kato Y, Collard BC, Septiningsih EM, Ismail AM (2014) Physiological analyses of traits associated with tolerance of long-term partial submergence in rice. AoB Plants 6:plu058

Kobayashi S, Fukuta Y, Sato T, Osaki M, Khush G (2003) Molecular marker dissection of rice (Oryza sativa L.) plant architecture under temperate and tropical climates. Theor Appl Genet 107(8):1350-1356

Kretzschmar T, Pelayo MAF, Trijatmiko KR, Gabunada LFM, Alam R, Jimenez R, Septiningsih EM (2015) A trehalose-6-phosphate phosphatase enhances anaerobic germination tolerance in rice. Nat Plants 1(9):15124. doi:10.1038/ nplants.2015.124

Lanceras JC, Pantuwan G, Jongdee B, Toojinda T (2004) Quantitative trait loci associated with drought tolerance at reproductive stage in rice. Plant Physiol 135(1):384-399

Li Z, Pinson S, Park W, Paterson A, Stansel J (1997) Quantitative trait Loci associated with drought tolerance at reproductive stage in rice. Plant Physiol 135:384-399

Li J, He P, Zheng X, Lu R, Zhu L (1998) Identification and interaction analysis of six agronomic trait loci of rice based on a recombinant inbred population. Acta Bot Sin 41(11):1199-1203

Li Z-K, Yu S-B, Lafitte H, Huang N, Courtois B, Hittalmani S, Shashidhar H (2003) QTLX environment interactions in rice. I. Heading date and plant height. Theor Appl Genet 108(1):141-153

Li C, Zhou A, Sang T (2006) Genetic analysis of rice domestication syndrome with the wild annual species, Oryza nivara. New Phytol 170(1):185-194

Lian X, Xing Y, Yan H, Xu C, Li X, Zhang Q (2005) QTLs for low nitrogen tolerance at seedling stage identified using a recombinant inbred line population derived from an elite rice hybrid. Theor Appl Genet 112(1):85-96

Lin H, Ashikari M, Yamanouchi U, Sasaki T, Yano M (2002) Identification and characterization of a quantitative trait locus, $\mathrm{Hd}$, controlling heading date in rice. Breed Sci 52(1):35-41

Lu C, Shen L, He P, Chen Y, Zhu L, Tan Z, Xu Y (1997) Comparative mapping of QTLs for agronomic traits of rice across environments by using a doubledhaploid population. Theor Appl Genet 94(1):145-150

Mackill DJ, Ismail AM, Pamplona AM, Sanchez DL, Carandang JJ, Septiningsih EM (2010) Stress tolerant rice varieties for adaptation to a changing climate. Crop Environ Bioinformatics 7:250-259

Manly KF, Cudmore RH Jr, Meer JM (2001) Map Manager QTX, cross-platform software for genetic mapping. Mamm Genome 12(12):930-932

Marri PR, Sarla N, Reddy LV, Siddiq E (2005) Identification and mapping of yield and yield related QTLs from an Indian accession of Oryza rufipogon. BMC Genet 6(1):33

McCouch SR (2008) Gene nomenclature system for rice. Rice 1(1):72-84

Mei H, Luo L, Ying C, Wang Y, Yu X, Guo L, Li Z (2003) Gene actions of QTLs affecting several agronomic traits resolved in a recombinant inbred rice population and two testcross populations. Theor Appl Genet 107(1):89-101

Mei H, Li Z, Shu Q, Guo L, Wang Y, Yu X, Luo L (2005) Gene actions of QTLs affecting several agronomic traits resolved in a recombinant inbred rice population and two backcross populations. Theor Appl Genet 110(4):649-659

Moncada P, Martinez C, Borrero J, Chatel M, Gauch H Jr, Guimaraes E, McCouch S (2001) Quantitative trait loci for yield and yield components in an Oryza sativa $\times$ Oryza rufipogon BC2F2 population evaluated in an upland environment. Theor Appl Genet 102(1):41-52

Murray M, Thompson WF (1980) Rapid isolation of high molecular weight plant DNA. Nucleic Acids Res 8(19):4321-4326

Nagai K, Kondo Y, Kitaoka T, Noda T, Kuroha T, Angeles-Shim RB, Ashikari M (2014) QTL analysis of internode elongation in response to gibberellin in deepwater rice. AoB Plants 6:plu028

Nagata K, Fukuta Y, Shimizu H, Yagi T, Terao T (2002) Quantitative trait loci for sink size and ripening traits in rice (Oryza sativa L.). Breed Sci 52(4):259-273.

Neeraja CN, Maghirang-Rodriguez R, Pamplona A, Heuer S, Collard BC, Septiningsih EM, Mackill DJ (2007) A marker-assisted backcross approach for developing submergence-tolerant rice cultivars. Theor Appl Genet 115(6): 767-776. doi:10.1007/s00122-007-0607-0

Nelson JC (1997) QGENE: software for marker-based genomic analysis and breeding. Mol Breed 3(3):239-245

Price A, Young E, Tomos A (1997) Quantitative trait loci associated with stomatal conductance, leaf rolling and heading date mapped in upland rice (Oryza sativa). New Phytol 137(1):83-91 
Redfern SK, Azzu N, Binamira JS (2012) Rice in Southeast Asia: facing risks and vulnerabilities to respond to climate change. Build Resilience Adaptation Climate Change Agric Sect 23:295

Sarkar R, Panda D, Reddy J, Patnaik S, Mackill DJ, Ismail AM (2009) Performance of submergence tolerant rice (Oryza sativa) genotypes carrying the Sub1 quantitative trait locus under stressed and non-stressed natural field conditions. Indian J Agric Sci 79(11):876-883

Septiningsih E, Prasetiyono J, Lubis E, Tai T, Tjubaryat T, Moeljopawiro S, McCouch S (2003) Identification of quantitative trait loci for yield and yield components in an advanced backcross population derived from the Oryza sativa variety IR64 and the wild relative O. rufipogon. Theor Appl Genet 107(8):1419-1432

Septiningsih EM, Pamplona AM, Sanchez DL, Neeraja CN, Vergara GV, Heuer S, Mackill DJ (2009) Development of submergence-tolerant rice cultivars: the Sub1 locus and beyond. Ann Bot 103(2):151-160. doi:10.1093/aob/mcn206

Septiningsih EM, Collard BC, Heuer S, Bailey-Serres J, Ismail AM, Mackill DJ (2013a). Applying genomics tools for breeding submergence tolerance in rice. Transl Genomics Crop Breed 2:9-30.

Septiningsih EM, Ignacio JCl, Sendon PM, Sanchez DL, Ismail AM, Mackill DJ (2013b). QTL mapping and confirmation for tolerance of anaerobic conditions during germination derived from the rice landrace Ma-Zhan Red. Theor Appl Genet 126(5):1357-1366.

Septiningsih EM, Hidayatun N, Sanchez DL, Nugraha Y, Carandang J, Pamplona AM, Mackill DJ (2015) Accelerating the development of new submergence tolerant rice varieties: the case of Ciherang-Sub1 and PSB Rc18-Sub1. Euphytica 202(2):259-268

Singh S, Mackill DJ, Ismail AM (2009) Responses of SUB1 rice introgression lines to submergence in the field: yield and grain quality. Field Crop Res 113(1):12-23

Singh S, Mackill DJ, Ismail AM (2011) Tolerance of longer-term partial stagnant flooding is independent of the SUB1 locus in rice. Field Crop Res 121(3):311-323

Singh S, Mackill DJ, Ismail AM (2014). Physiological basis of tolerance to complete submergence in rice involves genetic factors in addition to the SUB1 gene. AoB Plants 6. doi:10.1093/aobpla/plu060

Takeuchi Y, Hayasaka H, Chiba B, Tanaka I, Shimano T, Yamagishi M, Yano M (2001) Mapping quantitative trait loci controlling cool-temperature tolerance at booting stage in temperate japonica rice. Breed Sci 51(3):191-197

Thomson MJ (2014) High-throughput SNP genotyping to accelerate crop improvement. Plant Breed Biotechnol 2(3):195-212

Thomson M, Tai T, McClung A, Lai X, Hinga M, Lobos K, McCouch S (2003) Mapping quantitative trait loci for yield, yield components and morphological traits in an advanced backcross population between Oryza rufipogon and the Oryza sativa cultivar Jefferson. Theor Appl Genet 107(3):479-493

Toledo AMU, Ignacio JCI, Casal C, Gonzaga ZJ, Mendioro MS, Septiningsih EM (2015) Development of improved Ciherang-Sub1 having tolerance to anaerobic germination conditions. Plant Breed Biotechnol 3(2):77-87

Venuprasad R, Bool M, Quiatchon L, Cruz MS, Amante M, Atlin G (2012) A largeeffect QTL for rice grain yield under upland drought stress on chromosome 1. Mol Breed 30(1):535-547

Vergara GV, Nugraha Y, Esguerra MQ, Mackill DJ, Ismail AM (2014) Variation in tolerance of rice to long-term stagnant flooding that submerges most of the shoot will aid in breeding tolerant cultivars. AoB Plants 6:plu055

Wang S, Basten C, Zeng Z (2010) Windows QTL Cartographer 2.5. 2007. Department of Statistics, North Carolina State University, Raleigh

Xiao J, Li J, Yuan L, Tanksley S (1996) Identification of QTLS affecting traits of agronomic importance in a recombinant inbred population derived from a subspecific rice cross. Theor Appl Genet 92(2):230-244

Xing Y-Z, Xu C-G, Hua J-P, Tan Y-F (2001) Analysis of QTL x environment interaction for rice panicle characteristics. Yi Chuan Xue Bao 28(5):439-446

Yan J, Zhu J, He C, Benmoussa M, Wu P (1999) Molecular marker-assisted dissection of genotype $\times$ environment interaction for plant type traits in rice (Oryza sativa L.). Crop Sci 39(2):538-544

Yan C-J, Liang G-H, Chen F, Li X, Tang S, Yi C, Gu M (2003) Mapping quantitative trait loci associated with rice grain shape based on an indica/japonica backcross population. Yi Chuan Xue Bao 30(8):711-716

Yonemaru J-i, Yamamoto T, Fukuoka S, Uga Y, Hori K, Yano M (2010) Q-TARO: QTL annotation rice online database. Rice 3(2-3):194-203

Yoon D-B, Kang K-H, Kim H-J, Ju H-G, Kwon S-J, Suh J-P, Ahn S-N (2006) Mapping quantitative trait loci for yield components and morphological traits in an advanced backcross population between Oryza grandiglumis and the 0 . sativa japonica cultivar Hwaseongbyeo. Theor Appl Genet 112(6):1052-1062
Yu S, Yang C, Fan Y, Zhuang J, Li X (2008) Genetic dissection of a thousand-grain weight quantitative trait locus on rice chromosome 1. Chin Sci Bull 53(15): 2326-2332

Yue B, Xue WY, Luo LJ, Xing YZ (2006) QTL analysis for flag leaf characteristics and their relationships with yield and yield traits in rice. Acta Genet $\operatorname{Sin} 33(9)$ : 824-832.

Zhuang J-Y, Fan Y-Y, Rao Z-M, Wu J-L, Xia Y-W, Zheng K-L (2002) Analysis on additive effects and additive-by-additive epistatic effects of QTLs for yield traits in a recombinant inbred line population of rice. Theor Appl Genet 105(8):1137-1145

Zou G, Mei H, Liu H, Liu G, Hu S, Yu X, Luo L (2005) Grain yield responses to moisture regimes in a rice population: association among traits and genetic markers. Theor Appl Genet 112(1):106-113

\section{Submit your manuscript to a SpringerOpen ${ }^{\circ}$ journal and benefit from:}

- Convenient online submission

- Rigorous peer review

- Immediate publication on acceptance

- Open access: articles freely available online

- High visibility within the field

- Retaining the copyright to your article

Submit your next manuscript at $>$ springeropen.com 